\title{
INTEGRATED OPERATIONS PLAN
}

MACF"

mats

FOR THE

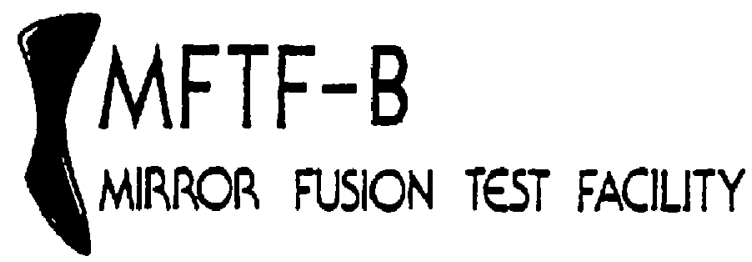

VOLUME II - INTEGRATED OPERATIONS PLAN

LAWRENCE LIVERMORE NATIONAL LABORATORY UNIVERSIT: OF CALIFORNIA

\section{pre}




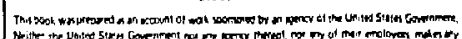

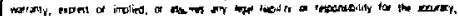

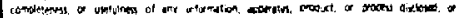

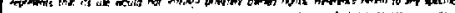

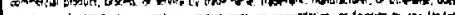

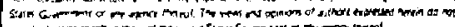

DECEMBER 1981

\section{INTEGRATED OPERATIONS PLAM}

FOR THE

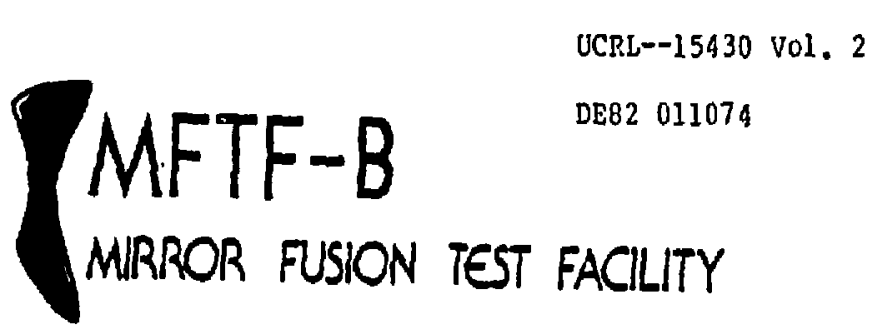

\section{VOLUME $\|$ - INTEGRATED OPERATIONS PLAN} UNIVERSITY OF CALIFORNIA 


\section{MFTF-B}

INTEGRATED OPERATIONS PLAN

\section{TAQLE OF CONTENTS}

$\underline{\text { Section }}$

Title

Page

1.

PIRPOSE $\ldots \ldots \ldots \ldots \ldots \ldots \ldots \ldots$

2.

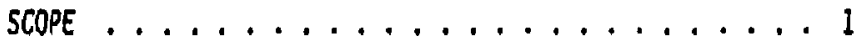

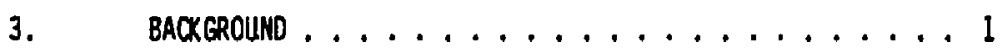

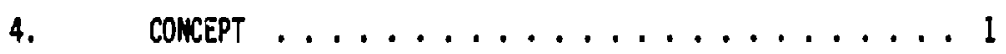

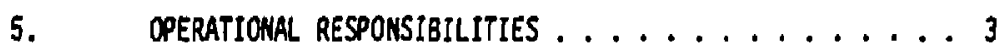

6. REQUIRED functions $\ldots \ldots \ldots \ldots \ldots \ldots$

Attachment

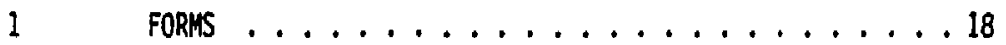

Appendix

1 RELIABILITY, QLULITY ASSURAMCE, AMO SAFETY PLAM . . . . 31

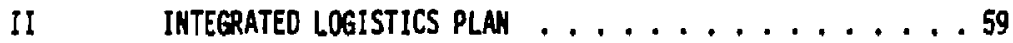


INTEGRATED OPERATIONS PLAN FOR

THE MIRROR FUSION TEST FACILITY - B

\subsection{PURPOSE}

This document defines an integrated plan for the operation of the Lawrence Livermore National Laboratory (LLML) Mirror Fusion Test Facility (MFTF-B). The plan fulfills and further delineates LLNL policies and provides for accomplishing the functions required by the program.

\subsection{SCOPE}

This plan specifies the managenent, operations, maintenance, and engineering support responsibilities. It covers phasing into sustained operations as well as the sustained operations themselves. Administrative and Plant Engineering support, wich are now being performed satisfactorily, are not part of this plan unless there are unique needs.

\subsection{BACKGROUHD}

The MFTF-B will be a national resource with the potential for a major positive contribution to easing the world's energy problens. The magnitude and complexity of this investwent require a fomal approach to the managenent of experimentation, operation, maintenance, and engineering support for maximum effective utilization of the test facility.

\subsection{CONCEPT}

The operational goill of MFTF-B is to produce the best quality and largest quantity of required experimental data practical from the resources comitted to this project. This plan's soncept for accomplishing this goal includes:

a. Assuring the theoretical physicist is involved in establishing criteria for every experinent 
b. Relieving the physicist of involvenent with details that do not require his expertise

c. Assuring the documentation and the hardware are in agreement

d. Providing the traceability of all exper iment configurations

e. Requiring proper reyiew of problems and proposed solutions

f. Involving the operatfons personnel in maintenance, improvenents, requirement changes, and problem resolution

g. Insuring all changes are analysed for impact to reliability, logistics, safety, operations, maintenance, other systems, schedules, and cost prior to implenentation

h. Furnishing the manager sufficient programmatic and technical information to permit informed decisions to be made

To achieve the above, the concept requires definitive responsibilities with necessary aithority combined to perform (or have performed) all functions inherent in this project. Project positions that are necessary with in a larger matrix organization are: MFTF-B Project Manager (PM) for LLNL, Associate Project Manager for Physics (APMP), Associate Project Manager for Operations and Maintenance (APMOM), and Associate Project Manager for Engineering (APME).

The coordination, concurrences, and boards that are cited later in this plan are methods for keeping the responsible position-holders fully informed and to essure the decision-maker has the best possible information on wich to base action. Inputs and concurrences are not mandatory prior to taking action, but their omission may endanger good commenications and optinum decisions. 


\subsection{OPERATIONAL RESPONSIBILITIES}

Experimental projects utilizing large facilities usually have five distinct elements: project managenent, experimentation criteria development, facility operations, resulting data analys is, and engineering support. Besides these usual tasks, MfTF-B will involve development of plasma measuring instrumentation, beam source improvement, and expanded use of RF heating. State-of-the-art engineering improvements in fusion reactors, vacuum technology, cryogenic systens, and gas handling equipment may be required to successfully complete the project. Responsibilities for elements can be combined or divided but they must not be ignored for a successful long-range progran. This plan proposes to organize these elenents into an entity.

\subsection{PROJECT MANAGEMENT}

The MFTF-B PM is the representative of the contractor to the Department of Energy (DOE) and the purchaser of goods and services from the line and support organizations of LLNL. He shall approve the general criteria for experiments and all schedule milestones and provide resources necessary for performance. He is responsible for the total integration of all elements of this project, including planning, budgeting, and allocation of time and resources. All future requirements, funding, and schedules and their changes shall be controlled by the PM, and he is responsible for all necessary programatic support.

In accomplishing the duties of project managenent, the PM will be assisted by a Project Planning and Control office. The office shall maintain status and advise him as to the conditions of schedules, budgets, funding, expenditures, managenent effect iveness, changes, and future planning.

As new data develop, the PM must be flexible and resourceful in planning new scenarios and convincing LLML management or the DOE Program Director of the advisability of increased (or decreased) project scope and required resources. The ability to exploit new opportunities as they develop may well determine the success of the project. 


\subsection{PHYSICS}

The APMP shall prepare an Experimentation Plan for the PM's approval. The plan will be the basis for an agreenent with DOE of the project's intermediate goals and the approaches to be used. The Experimentation PIan will be separated by class of objectives and further expanded into Exper imentation Criteria by the Physics Experimentation Leaders (for APMP approval). The criteria define the facility beam and diagnostic support and conditions necessary and the data required for analysis.

The Physics Experimentation Leaders wil: prepare detailed plans for processing the information collected from MFTF-B diagnostics as a result of shots performed in compliance with the Experimentation Criteria. The direct responsibility for data evaluation, interpretation, and report preparation is that of the Physics Experimeritation Leaders for the findings produced from his Experimentat ion Criteria. The results of the analyses may provide a basis for revisions to the Experimentation Criteria. When analyses indicate needed revisions to the Experimentation Plan or to the MFTF-B Facility, the PM will be informed.

Quick look data analyses will be performed after most shots and at the end of each shift. The AProl will participate in assessing inpacts and potential impacts to the facility operations. The results of the shift quick look will be made available to the physics leader of the following shift.

The APIP is respons ible for physics irput to progress, special, annual, and final Project Reports. Physics report preparation will be prepared under the supervision and for the approval of the Apip.

\subsection{FACILITY OPERATLONS}

The purpose of this project is to utilize the facility for a succession of exper iments to produce data. In addition, the operation of the facility should provide an engineering data base for future fusion devices and may provide a test data base for component development and related engineer ing research. Facility operations as used here is defined to include: 
a. Performing actual experiments

b. Collecting experimental data

c. Preparing, operating, maintaining, and modifying all MFTF- 8 dedicated facilities and equipment

The APMOH shall be responsible for facility operations and facility availability. The Manager must assure all hardware has the proper configuration; Operations and Maintenance (O\&M) Manuals and documentation available to him are current; spares and repair capability are available; and operations, maintenance, ar:a modifications comply with approved schedules. Improvenents to increase availability, enhance production, minimize costs, and reduce personnel requirements shall be goals of operations; however, no changes shall be made except in accordance with released documentation. Technical, budget, and schedule proposals will be developed for submittal to the PM upon his request. The APMoN must be able to accomodate frequent changes in daily operations as experimental results, equipment performance, and new areas for investigat ion impact the daily working plan.

The APMOM is respons ible for the onsite safety of the facility, equipment, and personnel during the operating and maintenance cycles. When modifications are being perfomed under the supervision of the APMMM, safety respons ibility also rests with the APIMN.

\subsection{ENGINEERING SUPPORT}

Support engineering will be required. An APME will be the focal point. Some areas that may demand support are safety, reliability and quality assurance engineering, logistics, documentation control and repository, and des ign and system analys is (this includes evaluation of proposed changes, design concepts, trade studies, problen investigations, oem improvenents, etc). Proposed budgets of time and resources shall be prepared upon the request of the PM. Engineering experts will serve as consultants to the Oer and physics areas. 


\subsection{REQUIRED FUNCTIONS}

\subsection{PROJECT PLARHING AHO CONTROL}

The PM is solely respons ible for the required Project Managenent functions. The $P M$ is assisted by a Project Planning and Control (PP\&C) Office. For the approval of the PM, the office will facilitate the following:

6.1.1 PROJECT PLAK. The Project Plan states the long- and short-range progran goals, schedules, and estimated costs. A common understanding with DOE must frame the Project for all areas of LLIL. The PP\&C will revise the Project PIan as required by progran changes. The revisions will be for the approval of the PIM.

6.1.2 FISCAL CONTROL. The Project operating budgets will be developed utilizing inputs from the APMOM, APMP, and APME. The PPEC will compile and collect justifications for MFTF-B budget and funding requests for the PM. Project expenditures will be controlled by the PM using current funding and expenditure status that is maintained by the Pp\&C. The project status will convey this datum.

6.1.3 CONFIGLRATION MANAGEMENT, Conf iguration Management cons ists of basel ining hardware, software, and documentation, control of changes, and an audit system to identify baseline versus changes at all tines. A Conf iguration Management Plan shall be developed by PP\&C for the approval of the PH. The plan will def ine the steps required for adequate control of the configuration.

6.1.3.1 Baseline. After acceptance testing of each subsystem, the Construction Project Managenent Tean shall assure the hardware, software, and the engineering documentation required for operating, maintaining, and design changes are present and in agreenent, thus constituting the MFTF-B configuration baseline. No change shall be made to this hardware, software, or documentation that modifies fit or function without the prior approval of the PM. 
6.1.3.2 Change Control. Changed requirements, operat ional improvenents, problem resolutions, cost reductions, and reliabilityisafety improvenents shall be analysed and scheduled with the resources allocated and approved prior to any changes to the baseline. Figure 1 depicts the processing of changed requirements, product improvements, cost reductions, or other types of changes to the baseline. Upon approval of the change, a Configuration Control Board Directive will be issued. Figure 2 shows the activity required when the directive requires a design to be prepared. PP\&C will maintain the status of all approved and un approved changes.

\subsubsection{Auditing. Support Engineering must continually maintain the} documentation baseline plus all approved released changes. The operators shall maintain equipment/facility logs that will identify the history of hardware changes and other significant events. These two data bases of technical fact5, supplemented by PP\&C status of unapproved changes and approved but unreleased modifications, will furnish a complete audit trail of all actions affecting the baseline.

\subsubsection{Configuration Control Board (CCB). The CCB functions as an aid to the} PM by assuring each organization impacted is fully informed and is given the opportunity to be heard prior to decisions on establishing new baselines and on proposed changes to requirements, hardware, docunentation, and software that affect baselines. PP\&C is the secretariat to the board. Physics, O\&M, and Engineering have permanent members and Hazards Control should have a representative who can be called upon when that area of expertise is needed by the board. Each board nember must coordinate within his ow organization to assure all involved skills and activities are fully represented.

\subsubsection{PROJECT STATUS. The LLKL Managenent Information System (MIS) comitined} with the lork Breakdom Structure (WBS) will serve as the primary system for project status. The MIS will track all open wrk including changes. Each organization supporting MFTF-B shall submit a report of its progress (or lack of progress) for inclusion into the MIS. 


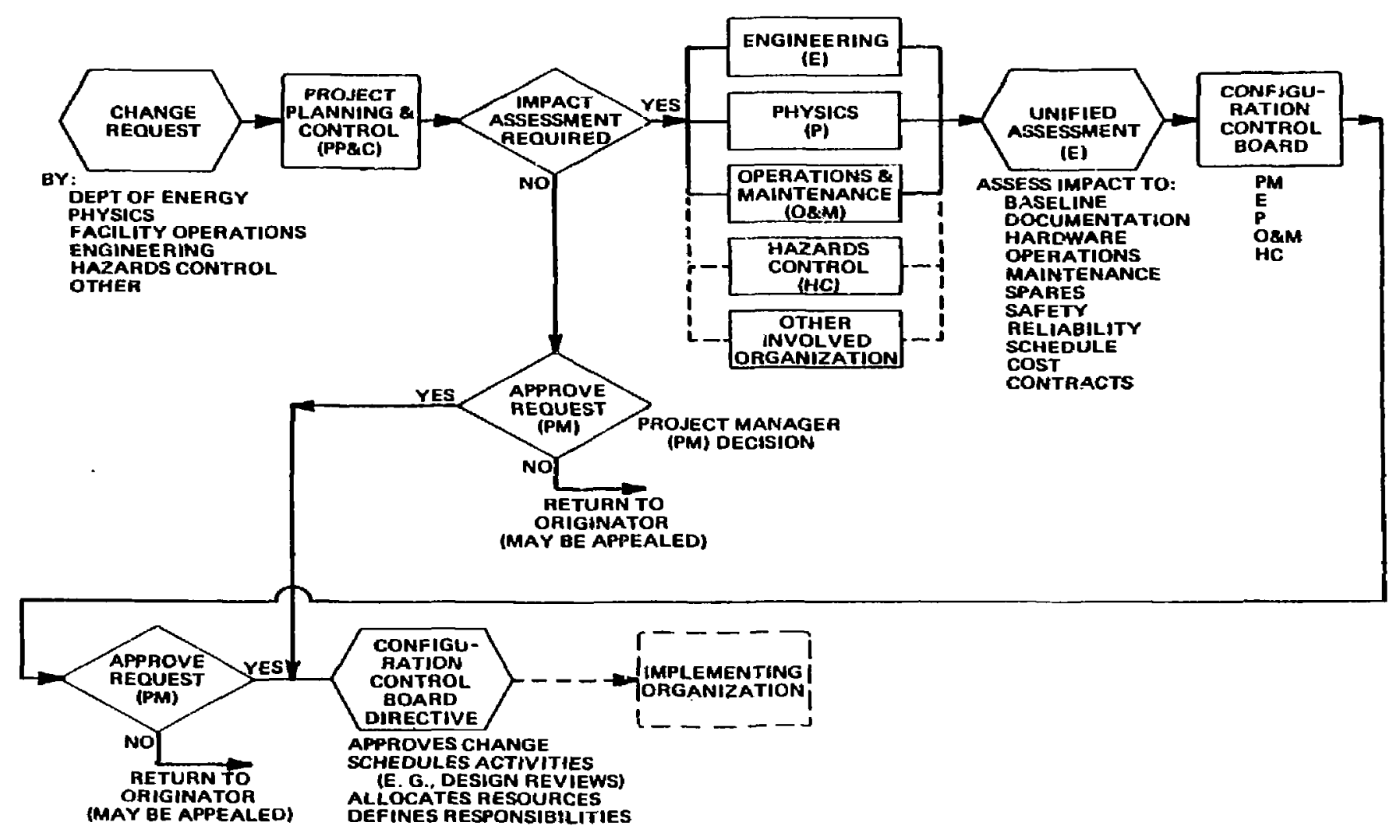

Figure 2. Change Request Processing 
(MAY BE APPEALED TO PM)
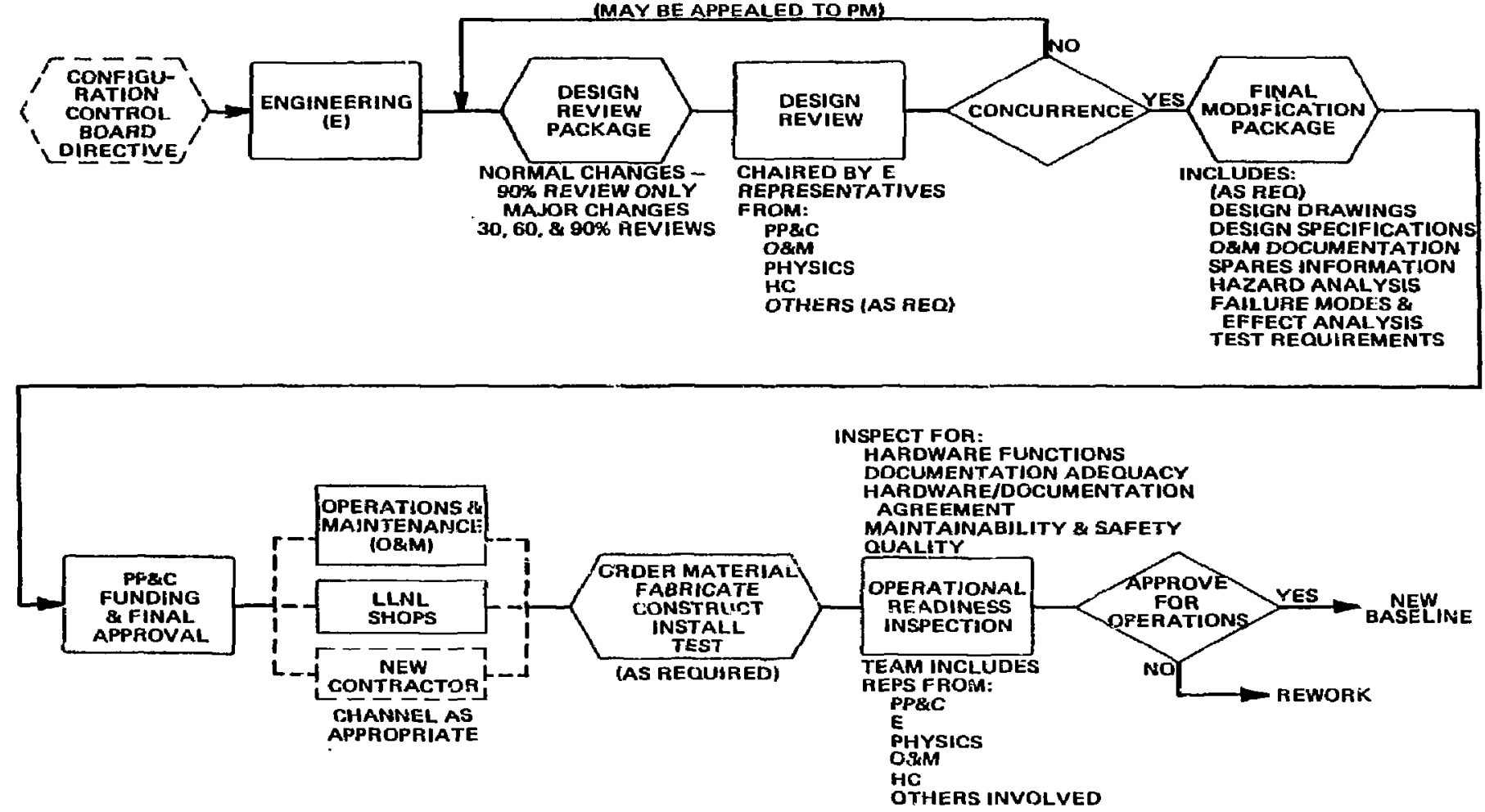

Figure 2. Design Chinge Directive Processing 


\subsubsection{AjTOMATION COMMITTEE. At his discretion, the Project Manager may}

establish special committees. An example could be an Automation Comittee to review project operations, data processing and reduction, or proposed major modifications. The objective of the Comittee would be to determine the kind and amount of automation most effective in view of on hand personnel and equipment, the changes planned for the future, and the latest advancements in equipment. Members on the Committee should represent the involved areas (hardware system designer, system operator, computer hardware, computer software, and project planning and control). Findings shall be in the form of recormendations to tha Project Manager with rationale.

\subsection{PAYSICS}

The following physics functions will be required during the project. To ensure organization and control while allowing the necessary flexibility, each plan will be reviewed and revised to reflect new information provided by experiments, new theoretical developments, budget changes, technological developments, reactor designs and other external factors. Technical, schedule, and cost changes must be approved by the PM.

\subsubsection{EXPERIMENTATION PLAN. This plan shall add detajl to the Project Plan and} can be an input into the Project Plan. After review by facility operations and support engineering and approval by the PM, the plan shall becone a control document within the MTF-B Project. Revisions may be approved by the PM as required.

\subsubsection{EXPERIMENTATION CRITERIA. Criteria must be developed to furnish the} facility cisations firm guidance as to the desired and minimum acceptable configurations and experimental data. Within the approved schedule, a more detailed matrix of requirements with associated diagnostics shall be developed by each Physics Experimentation Leader to allow a selection of shots. Preplanned directions will be furnished the "quick look tean" assuring the proper decisions will be made between shots and between shifts. 
6.2.3 DATA REDUCTION AND INTERPRETATION. The experiment is not complete until the information collected is analyzed, the ohenomenon interpreted as far as desired, and the results are adequately documented.

6.2.4 NEW CONFIGURATION CONCEPTS. Series of experiments may introduce as many questions as they answer. Changes in configuration must be considered. If new conf iguration concepts need engineer ing investigation or study, support may be obtained by using the Engineering Support Request form and process in accordance with figure 3. For baseline changes see figure 1 .

6.2.5 DIAGMOSTIC OEVELCPHEAT. The results of experimental runs may well indicate the need for new, additional, or expanded diagnostic measurement systems. As in 6.2.4 above, support or changes may be requested.

\subsection{OPERATING THE FACILITY}

A11 preparation, operations, maintenance, and modifications, as well as assuring the required normal and special support are available then needed, are activities encompassed by the team operating the facility.

\subsubsection{SPECIAL EQUIPMENT OPERATIOH. Certain equipment and diagnostics are at} the limits of the state-of-art for routine operations. Physics Special ists may be attached to the operating tean. The specialist will have two goals - successful equipment performance and reducing the operation to a documented rout ine that can be carried through by a trained techuician or a computer program.

6.3.2 MINTEMARCE. Maintenance is defined as those actions necessary to retain an iten in or to restore it to a specified condition. The maintenance concept is to renove and replace to the functional line replaceable unit (LRU) level, either on a scheduled basis as deternined from design characteristics or on an unscheduled basis as determined from malfunction. Repair-in-place may be accomplished only wen justified by the results of the naintenance analysis or as50ciated trade sti:ies. Maintenance nust be accomplished in a manner that will provide support of operational time constraints, prevent deterioration of reliability and operating safety, and accomplish this support and protection at minimun practical costs. In implementing the Integrated Logistics Plan (See 


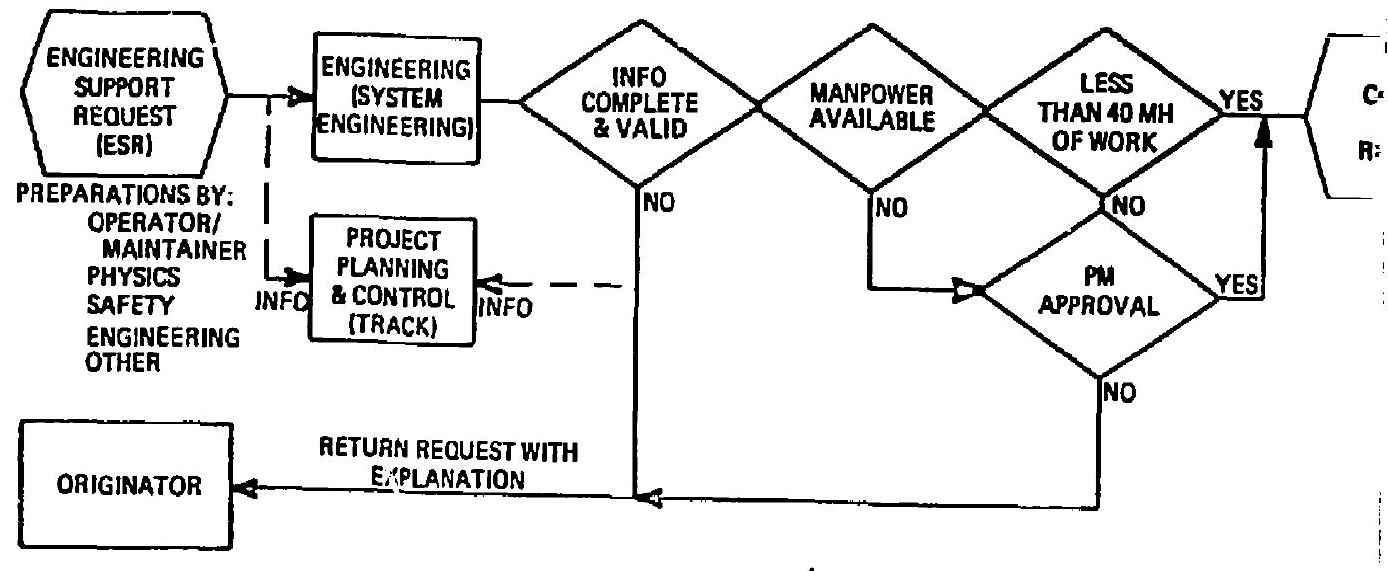

(A) GENE:

REQUESTS FOR INVESTIG." 


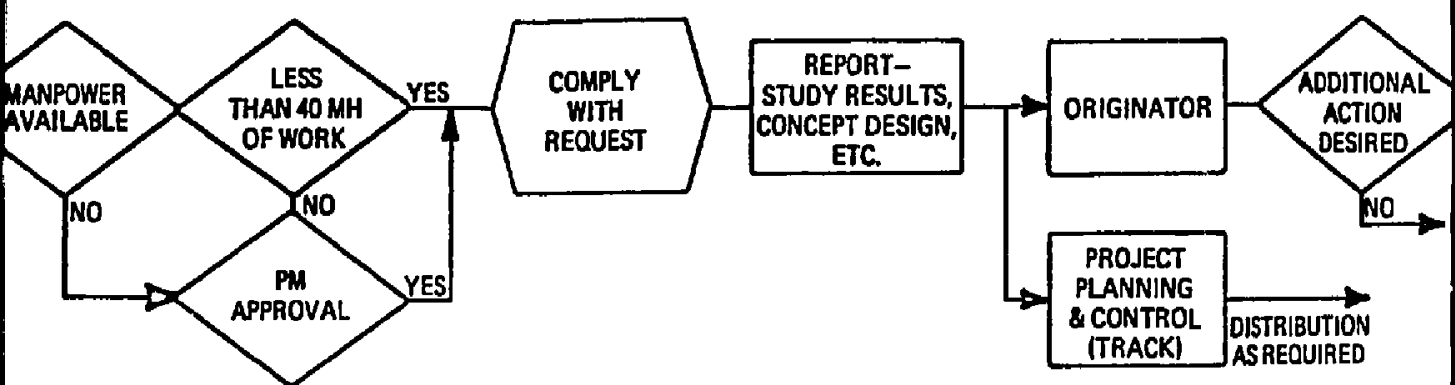

(A) GENERAL

REOUESTS FOR INVESTIGATIONS AND STUDIES

Figure 3. Engineering Support Request F1 
appendix (I), the operator will be involved in the preplanned preventive maintenance program to the largest extent practical to assure maximum facility availability for experimentation.

\subsection{EHGINEERING}

The experimental nature of the project and research goals of the facility indicate the strong need for a highly respons ive and skilled group of engineers. To attain and operate with high efficiency and reliability will involve product improvements. Developing new configurations to take advantage of new knowledge will demand flexibility. Supporting MFTF-B will require dedicated effort to establish and maintain the engineering configuration baseline under real time pressures. Functions required to accomplish follow.

6.4.1 SYSTEM ENGIMEERING. Using the classical breakdown, the system engineering functions are as follows.

6.4.1.1 Analysis. Investigations, trade studies, alternatives, life cycle costs, and change impacts fall into this area. For Engineering Support Request Flow see figure 3 .

\subsubsection{Logistics. Maintainability, maintenance studies, human factors, OSM documentation, and provisioning activities are performed as a part of this effort. Inputs to the living integrated logistics plans will originate from this work.}

\subsubsection{Reliability, Quality Assurance, and Safety. Engineering ass isted by} OsM will maintain a Reliability, Quality Assurance, and Safety Plan. See appendix I. Failures, problens, and their trends; requested improvenents and changes; and new designs and modifications will be assessed and recomendations will be made to assure safe and reliable operating conditions are maintained.

\subsubsection{DESIGN. The required design activities will involve the classic disciplines. The design group will furnish a stable pool of expertise to the project to aid in problem resolution; impact assessment of changes; design of modifications; and preparation of technical packages for procurement, fabrication, installation and acceptance testing of hardware and software.}




\subsubsection{Mechanical. Structures, cryogenics, fluids, and mechanical systems}

will require design attention as requirements change, product improvements develop, and new concepts evolve.

6.4.2.2 Electrical/Electronic. Power, controls, bean sources, measuring systems, computer with software and peripheral equipment, and data links are typical subjects for design effort.

\subsubsection{DOCUMENTATION. For good operations and communications, current and} readily available documentation is required. The engineering documentation furnishes one part of the configuration baseline; therefore, the documentation must be controlled.

\subsubsection{Engineering Documentation Control. The maintenance of accurate records} of the engineering document releases by date, effectivity, and authorization is mandatory. The approved documentation baseline will be readily available. Control will identify all Project actions (ESR's, CR's, etc.) into the engineering organization and close or suspense each as needed.

\subsubsection{Repository. A file of all released MFTF-B engineering will be main- tained. The repository will arrange for reproduction and distribution of documents when requested by the Document Release Authority (DRA) or by authorized personnel. The repository will se:ve all Project personnel.}

\subsection{INTEGRATED LOGISTICS}

The Integrated Logistics Plan for MFTF-B (see appendix II) contains details of logistic planning. Certain following logistics-related functions are of genera? interest.

\subsubsection{O\&M MANUALS. All major subsystens will have O\&M manuals to furnish the} operator when he assumes responsibility for the equipment. Simplified osu procedures shall be written by the APMOM for review by Engineering. If an engineering change affects a procedure, either a revision to the O\&M manual or O\&M criteria sheet(s) will specify mandatory actions. The APMOM shall update procedures as necessary. 


\subsubsection{BASELIME DOCLANENTS. Drawings and specifications required for}

fabrication, construction, and installation will probably greatly exceed 0\&M and baselining requirements. Early in the transition to an operational facility, the PN shall have the minimum documentation list for each subsystem defined. After agreenent, Engineering will maintain only listed documents. New schematics or other new documents may be highly desirable, but PW's approval must be given prior to expenditure for preparation.

\subsubsection{SPARES. A maintainability analys is will be performed as part of the de-} sign process to assure ready access, assist in troubleshooting, and that needed special tools will be provided. The support engineer shall recommend (or endorse manufacturer's recommendation) spares, who and where they will be stored, which itens are to be thrown away, which itens are to be repaired, and what contracts are needed (if any). Provisioning conferences composed of a respons ible operator, maintainer, designer, logistician, and a representative of the PM shou?d determine a joint position on all items not normally available at LLNL through normal supply. The PN should approve and fund the agreement and the maintainer should adjust maximum/minimum stock levels as experience dictates.

6.5.4 TRAIMING DOCUMENTATION. The goal is to require no special training documentation. Care shall be taken to assure all O\&H procedures, drawings, and other data are understandable by a qualified technician, thus avoiding misinterpretation and the necessit; for special training documentation.

\subsection{HA?.ARDS CONTROL EDUCATION}

The LLNL Hazards Control Educational Services will be used to train MFTF-B personnel concerning the hazards of radiation, high pressures, high vacuums, high volt ages, cryogenics, oxygen-starved atmospheres, hydrogen-enriched atmospheres, and high magnetism. Each will be potentially encountered in operations of the facility. Each supervisor is res, nsible for requiring the proper training of all subordinates that may enter a hazardous MFTF-B area. 


\section{ATTACHMENT 1}

FORMS

Enclosed are:

1.a CHANGE REQUEST

Form used in Figures 1 and 3

1.6 TECHNICAL IMPACT AND COST ESTIMATE

Form used in Figure 1

1.6 COMFIGLRATION COHTROL BOARD DIRECTIVE

Form used in Figures 1 and 2

1.d ENGINEERING SUPPORT REQUEST

Us:d in Figure 3, Appendix I Figure 2, and Appendix II

1.e HAZARD ANAL YSIS SHEET

Used in Appendix I Figure 3

1.f DOCUNENT CONTINLATION SHEET

Used with any of the previous forms as needed for additional space. 


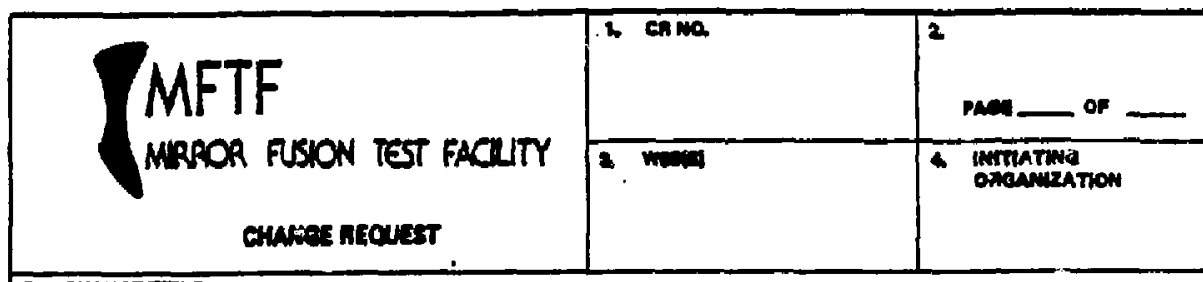

a cranatinu

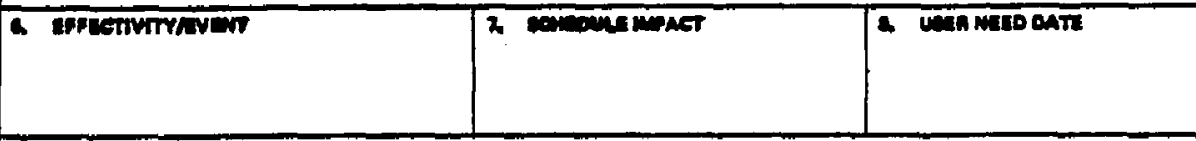

2 Dexeninew or cunve

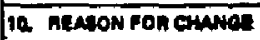

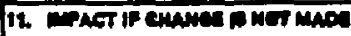

\begin{tabular}{|c|c|c|c|c|c|}
\hline . mananim & on & ann & GAMATUM & one. & DAT \\
\hline senmon & & & Armeveo or & & \\
\hline
\end{tabular}




\section{GEMERAL IHSTRUCTIOHS}

An MFTF Change Request (CR) shall be used when initiating changes to MFTF- $B$ controlled baselines. If the information requested by a block on the form is not known, or cannot be assessed at the time, that fact shall be noted on the form. Any backup data, sketches, draings, etc., wich will assist in evaluating the change shall be attached to the CR and the docunent(s) referenced on the CR. Document Continuation Sheets shall be used as necessary to fully document the proposed change.

If the change impacts MFTF-B Project baselines other than the LLNL MFTF-B controlled basellne, the Project Manager will prepare the necessary docunents requesting the change to be approved by the proper program authority.

2. COMPLETION INSTRUCTIONS

I The CR number will be provided by Project Planning and Control

2 The Hork Breakdown Structure (WBS) numbers will identify the facility/ system/itens to be changed.

3 Enter the page number and the total number of pages. Use Document Continuation Sheets as necessary.

4 Enter the name/symbol for the organization in which the change originates.

5 The change title is a brief statement by which the change can be recognized.

6 Identify the mission/event for which the change is proposed to support.

7 Identify any potential impact to major program or mission milestones.

8 Coordinate with the user prior to making this entry.

9 The description of the change includes a statement of the present baseline and a statenent of the proposei change.

10 Enter a statenent detailing the pertinent reason(s) for the proposed ch ange.

11 Describe the impact to the project/experiment of not approving the change.

12 Obtain the approval signature(s) of the individuals(s) authorized to submit change requests for the submitting organization. 


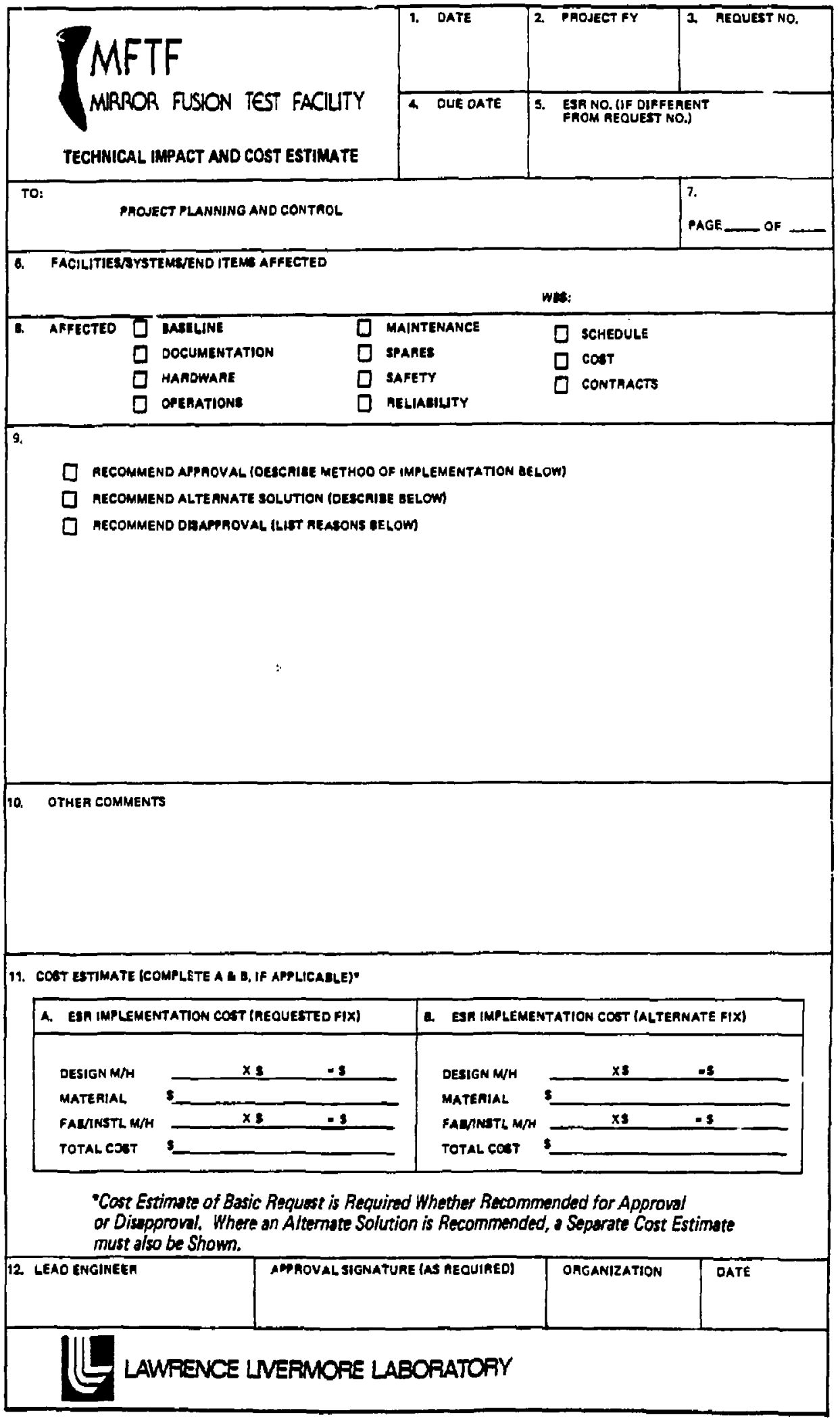




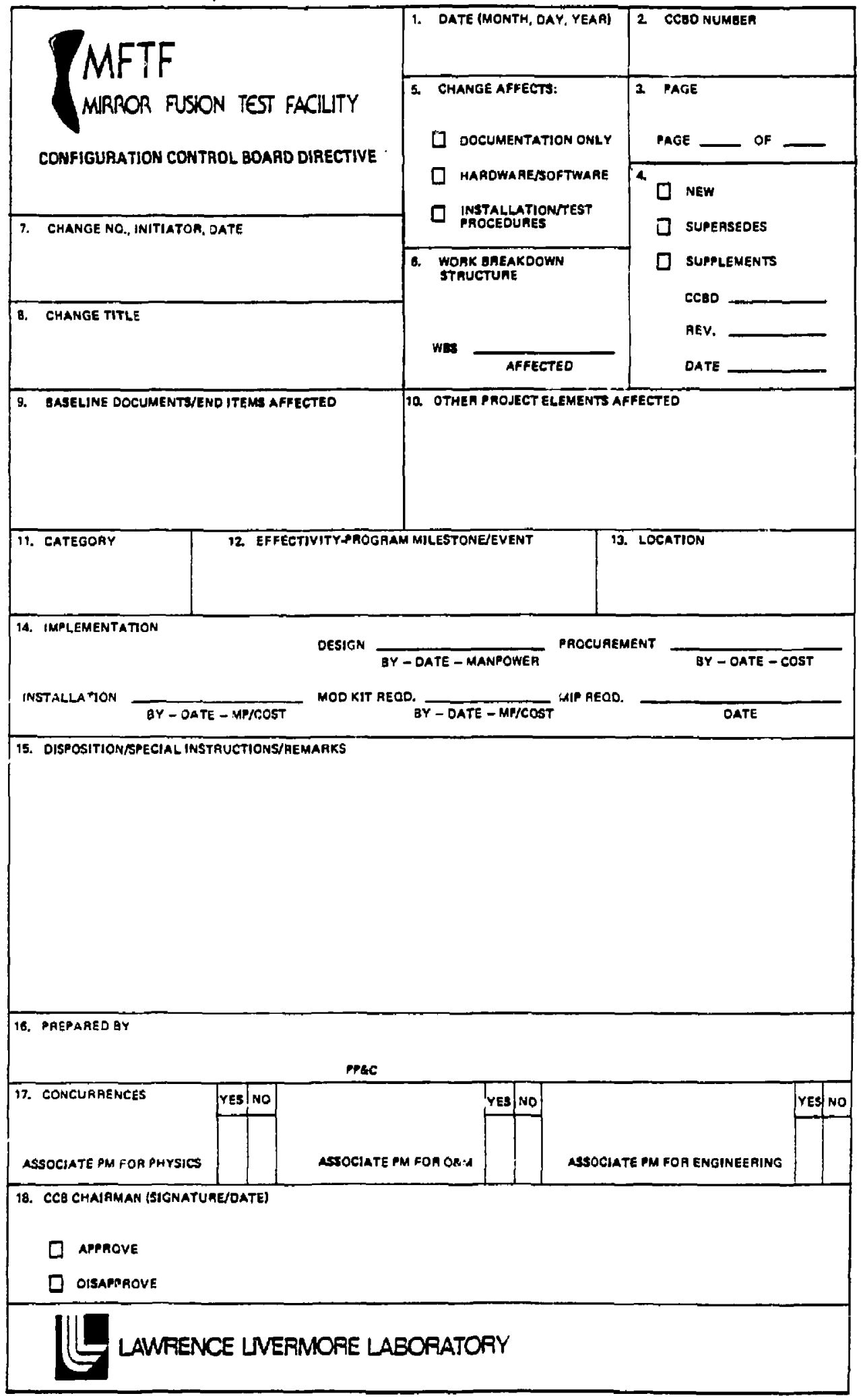




\section{COMPLFTIGN INS IRUCTIONS}

Complete each block on the form as follows:

1 Enter the date the CCBD is released (Month, Day, Year).

2 Enter the appropriate CCBD number after the CCB Chairman makes the change decision, signs, and dates the CCBO.

3 Insert the page number and the total number of pages for each C C 30 . use Document cont inuation Sheets as necessary.

4 Place an " $X$ " in the appropriate box to indicate whether the CCBD is new, supersedes, or supplements an active CCBD. The CCBD number, revision codn, and date of the active CCBD shall also be entered.

5 Place an "x" in the approp iate sox(es) to indicate what item(s) the proposed chanae affects: documentation, hardware/software, or installation/test procedures.

6 Enter the Work Breakdown Structure (WBS) no. of the impacted system(s).

7 Enter the identifying numbers of the proposed change, the date which appears on the proposed change, and the change initiator as identified in the change package.

8 Enter the title of the proposed change exactly as it appears in the change package.

9 List all documents/end items known to be affected by the proposed change including baseline documents, specifications, Interface control Documents, plans, procedures, manuals, drawings, etc.

10 Identify other Project Elements that have a direct relationship/ interface to the proposed change. Identify the CCBD number and CCBD date of tic af fected element( $s)$.

11 Indicate the category of the proposed change as it appears in the change packaqe (e.g., I and II). If the approved catesory differs from the recommended category, the CCBO must be "Approved with Changes Noted" in block 16.

12 Indicate the Program Milestone and/or Event for which the proposed change is planred.

13 Enter the location of the change, for example: third floor, building 431 .

14 Enter the appropriaif prganization respunsible for implementing design, procurement, insta istion, etc. Enter the date the Mod. Kit and/or MIP is reouired, approves manpower and funding by activity should be entered.

15 The preparer of the CCBD shall sign and date.

17 The CCB representative of each oroanization having a requirement to implement the provisions of the CCBD shall indicate $n$ is concurrence or nonconcurrence with the chaiman's decision by placing an "X" in the afpropriate box and signing the CCBO.

18 The CCB Chairman, after entering his change decision shall sign and date the CCBD. 
MFTF

MPROR FUSION TEST FACMITY ENGINEERING SUPPORT REQUEST

8. FACILITY/SYSTEMIEQUIPMENT WES 13. TITLE

19. DESCAJPTION OF REDUIREMENT/CONDITION/EVENT

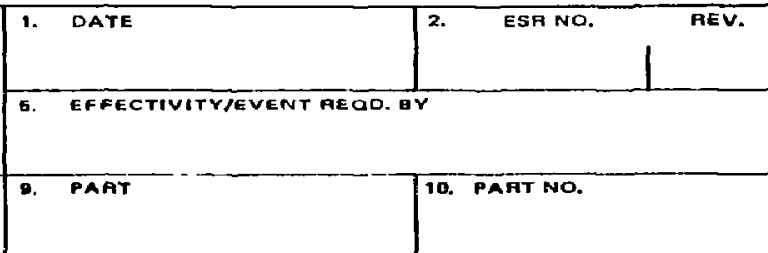

3. LOCATION
6. USEA NEED OATE
11. FINO NO.

17. ACTION FEOUESTED

is. JUSTIFICATION

19. COMMENTE AND ACTION UTEMS

20. TECHNICAL CONTACT

1 ORO. FHONE

21. PROJECT MANAGE A APM TIOVAL

aAtÉ

\section{DEEION ACCEPTANCE}

SIGNATUME

oคa.
7. CATEGT OF - MATY

14. TYPE OF ACTION

16. SCHEOULE IMPACT 


\section{ENGINEERING SUPPORT REQLEST (ESR)}

1. COMPLETION INSTRUCTIONS

Unless otherwise stated, requestor snall complete each block on the form as follows: (Enter "iva" when blor: is not applicable, leave blanix if nnt known. The items marked with an asterijx $(*)$ must be completed.

*1 Enter ESR preparation date.

*2 Enter the SSR number and ESR revision letter, as roguired. CDtair. ESR number from PPBL.

3 Self-explanatory.

4 Enter location (i.e., Building 439).

5 Enter date andior event that needs completed action.

6 Enter date by which request action is to be completed.

7 For proposed changes, enter either :landatory (Category () or High'y Desirable (Category?I).

a. Mandatory Changes - one or more of the following:

1) Hazardous condition exists that couid cause facal or serious injury to personnel or extensive damage or destruction of souijment.

2) A system equires to support a critical test is inoperable.

3) A change in operational characteristics develops that, if not acccmolished witnout delay, nay seriously delay the orogr am.

4) Conditions exist that require a cnenge to meat progran milestones.

D. Highly Desirable Changes - all other cnanges.

3 Enter the name of the facility/system/equipment, the request action, ard the work breakdown structure number.

9 Enter the nane of part the request action is against.

10 Enter the part number the request action is against.

11 Enter the find number the requesi action is against. Co iain tne rumber, if applicable, from the tag on the part, the OMD parts list, or orading.

-12 Enter descriotion title.

-13 Enter a complete detailed description of the reouirement, condition, and/or events. List all attacred documents. Any suggested methods of implementation snall be entered here.

14 Enter name c: manuf acturer of part, equipment, ets.

15 Enter type gi ection as follows:

a. New requirement

b. Change requirement

c. Replace like item

d. Deviation/waiver

e. Budoet requirement

f. Field engineering change

g. Repair

F. Disnosition instructions

i. Cannibalization

j. Studies

k. Other ispecify\}

16 Identify any potential impact major progran or tiission milestones.

-17 Enter descriptive parjgraph of action requested.

* Enter detailed justification for request. Cescribe the impact if request is not impleinented.

19 To be filled out by design. Enter any pertinent comments and ec: icns required to implement the request.

*20 Enter the name of the technical contact, the contact's orgarization and phone number.

21 Enter the -ignature and organization of the person of the originating organization approving the request and date of approval. Any concurrence required by the approving official may te entered in block 19 above the approval block; i.e., R\&CA, Safety, etc.

22 To be filled out by design.

NOT:: If additional space is required, use Document Cont inuation Sheet. 


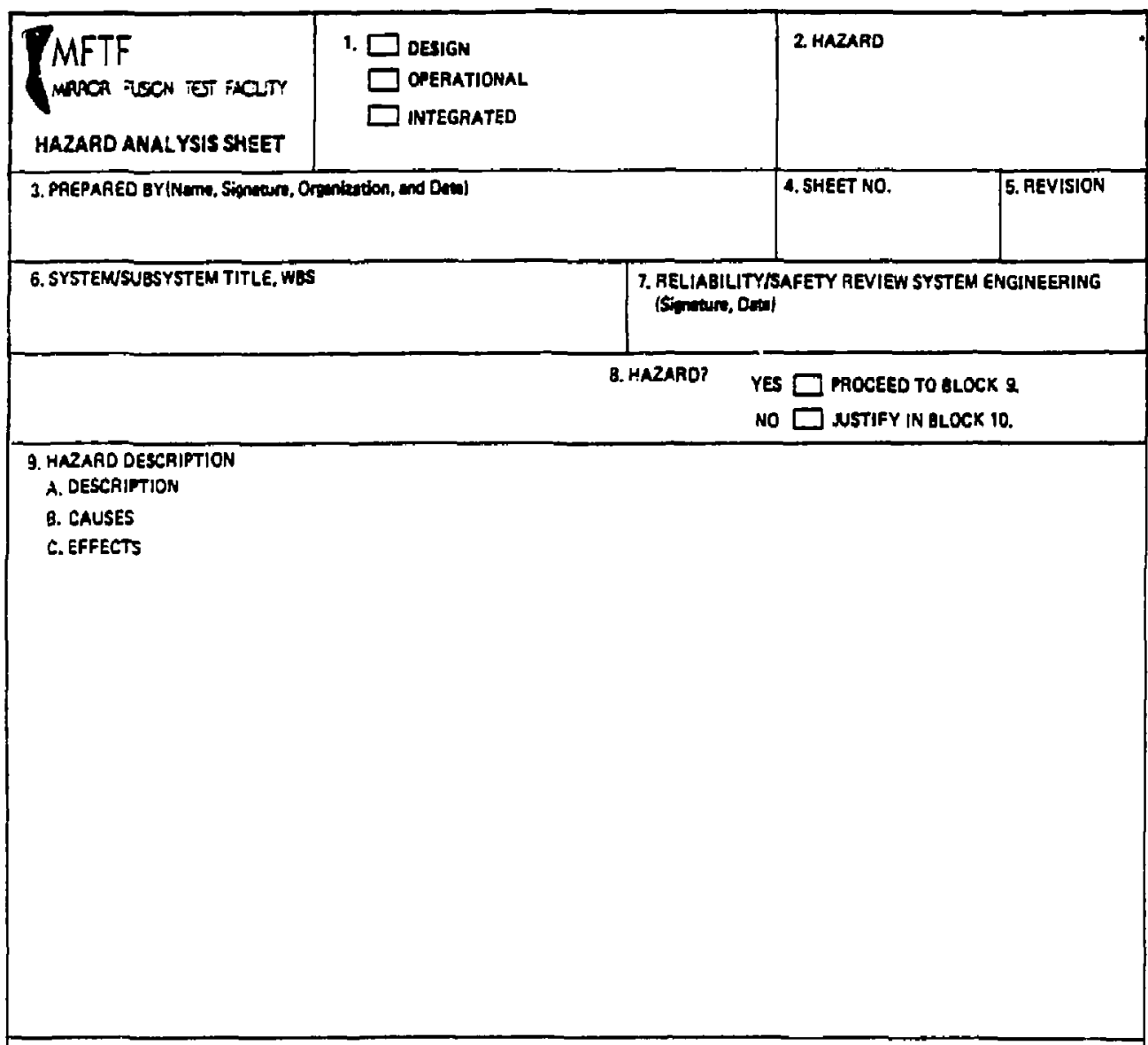

10. AESOLUTION 
1 Type hazard analysis.

2 Hazard analysis ident if ication number obtained from PP\&C.

3 Name, signature, and organization of engineer preparing form and the date.

- Sequential number of each Hazard Analys is Sheet for this system/subsystem.

5 If Hazard Analys is Sheet is revised, enter revision letter.

6 System/subsystom nomenclature and work breakdown structure.

7 Name and signature of reliability/safety reviewer and date.

8 Haz ard ident ified?

9 For an actual hazard identified, enter a:

a. Brief description of the nature of the hazard

b. Brief statement of cause of hazard

c. Statement of possible effects on personnel, equipment, or environment

10 if an identified noncompliance with a checklist item constitutes NO HAZARD, enter justification. If an actual hazard was identified, enter resoiution. If a hazard is considered an acceptable risk, enter rationale.

11 Check the appropriate box to indicate status of resolution and the appropriate level, either critical or catastrophic.

12 Concurrence signatures of Associate Project Manager required for controlled and residual hazards only.

13 Hazard control concurrence, controlled and res idual hazards only.

14 Project Manager's approval signature and date. 


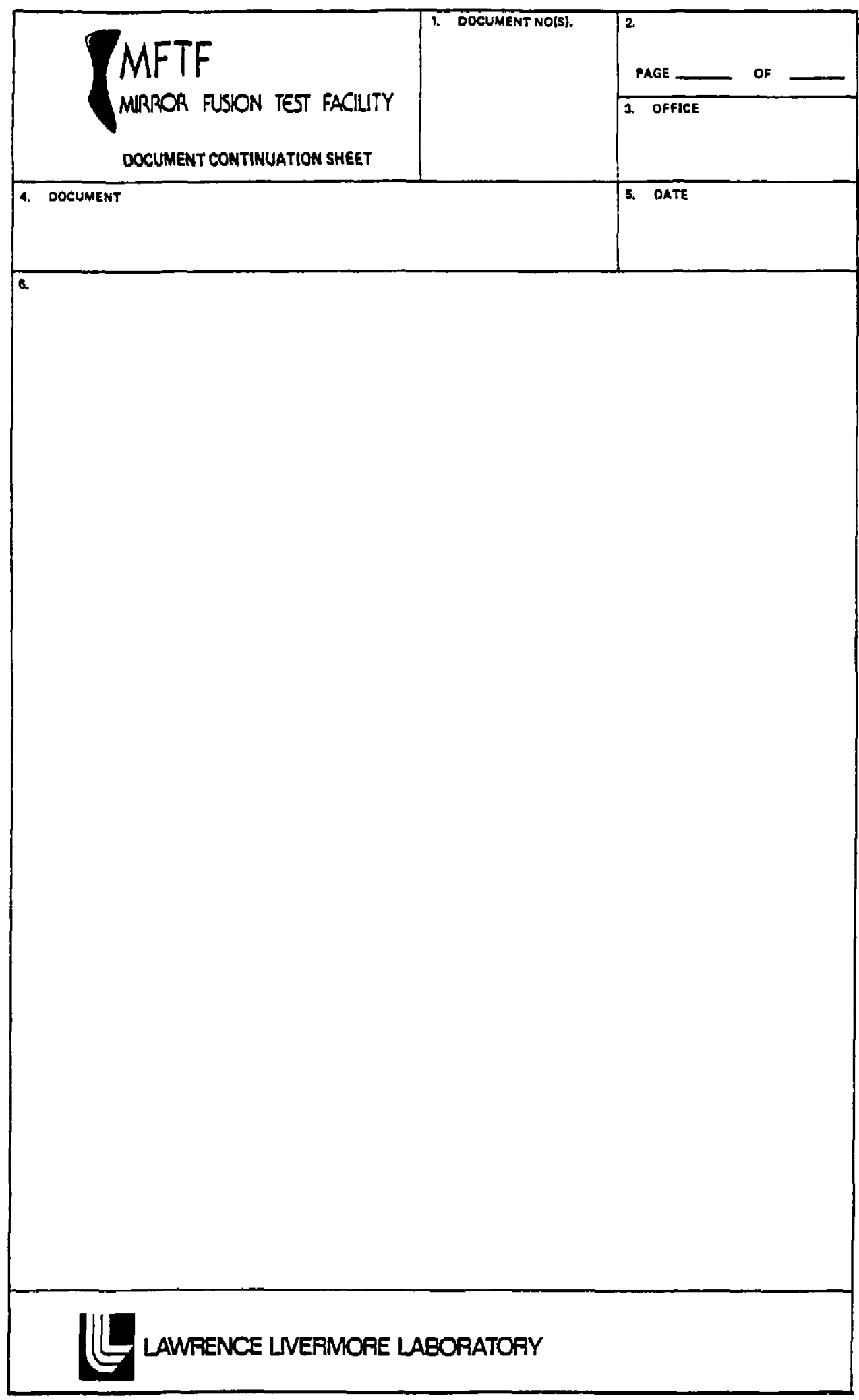




\section{GENERAL IMSTRUCTIONS}

An MFTF Continuation Sheet is provided as a general purpose continuation shee: for the "Change Request," the "Technical Impact and Cost Estimate," the Conf iguration Control Board Direct ives," and other MFTF documents as appropriate. The use of this standard form will aid change tracking, help pravide documentation clarity, and enable the documentation to be more casily understood.

\section{COMPLETE INSTRUCTIONS}

Complete each block on the form as follows:

1 Enter the same document number(s) appearing on the document being continued. For instance, if a $C R$ form is being continued, enter the $S R$ numbers in this block and if a CCBD is being continued, enter the CCBD number here.

2 Number each page as indicated. Use additiona! continuation sheets as necessary.

3 Enter the same office designation appearing on the dacument being continued.

4 Identify the document being continued.

5 Enter the same date appearing on the document being continued.

6 Ident ify by block title the block being continued. Insert "(cont)" and underline. Begin the continuation words on the next lower line. Any number of blocks can be continued on a single continuation sheet, but each block should be identified in the same manner. 


\section{APPENOIX I}

MFTF-B

MIRROR FUSION TEST FACILITY

RELIABILITY, QUALITY ASSURANCE, AND SAFETY PLAN 
MFTF-B

RELIABILITY, QUALITY ASSURANCE, AND SAFETY PLAN

TABLE OF CONTENTS

1. INTROOUCTION
1.1 Purpose
1.2 Scope and Applicability
1.3 Program Implementation

2. PROJECT ORGAHIZATIONS AMD RESPONSIBILITIES
2.1 Organizations
2.1.1 Project Management
2.1.2 Facility Operations
2.1.3 Engineering
2.1.4 Physics
2.1.5 Hazards Control

2.2 Task Responsibilities

3. ENGINEERING RELIABILITY ANO SAFETY FUNCTIONS

3.1 Determine Critical Systems and Equipment

3.2 Establish $R, Q A$, and $S$ Requirements

3.3 System Assurance Analys is (SAA)

3.3.1 FHEA and CIL

3.3.2 Systen Safety Guidelines and Constraints

3.3.3 Design Hazards Analys is (DHA)

3.4 Preparation Tracking System for Critical SFP's and Hazards

3.5 Coordinate Review and Acceptance of SFP's

3.6 Problem Report ing and Corrective Act ion System (PRACA)

3.7 Failure Analysis and Problen Analys is

3.8 Procurement Documentation

3.9 Component Qual if ication

3.10 Limited Life Hardware

3.11 Design Reviews

4. ENGIHEERING QUALITY ASSURANCE FUNCTIOHS
4.1 Quality Assurance Requirements
4.2 Procurement Docimentation
4.3 Support Requests
4.4 Quality Surveillance

5. OPERATING QUALITY ASSURANCE FUNCTIONS

6. OPERATING SAFETY FUNCTION

6.1 Operational Hazards Analys is 
MFTF-B

MIRROR FUSION TEST FACILITY

LAWRENCE LIVERMORE MTIOMAL LABORATORY

RELIABILITY, QUALITY ASSURANCE, AND SAFETY PLAN

\section{INTRODUCTION}

\subsection{PURPOSE}

This Reliability, Quality Assurance, and Safety ( $R, Q A$, and S) Plan defines the $R, Q A$, and $S$ program for the Mirror Fusion Test Facility (MFTF-B) project that fulfills Lawrence Livermore National Lajoratory (LLNL) policies and provides for the accomplishment of the functions comprising the program.

\subsection{SCOPE AND APPLICABILITY}

This plan specifies the $R, Q A$, and $S$ tasks to be considered for implementation during the operations of and the design/construction of modifications to the facilities, systems, and equipment for wich this project is responsible. The plan is applicable to all elements of LLNL as specified.

\subsection{PROGRAM IMPLEMENTATION}

In the implementation of $R, Q A$, and $S$ tasks contained herein, consideration shall be given to the complexity, supplier experience, state of hardware development, unit cost, and usage of the facility, system, or equipment. This plan is implemented through project directives and internal $R, Q A$, and $S$ procedures. 


\section{PROJECT ORGANIZATIONS AND RESPONSIBILITIES}

\subsection{ORGANIZATIONS}

\subsubsection{PROJECT MRNAGEMENT.}

a. Project Manager (PM). The PM is respons ib le for collect ing or estabiisning project/progran requirements and policies for the MFTF-B project at LLNL and approving the $R, Q A$, and $S$ efforts and risks to be taken with in the project.

b. Project Planning and Control (PP\&C). The PP\&C of fice will monitor and track, propose procedures and policies, and recommend positions and act ions concerning $R, Q A$, and $S$ for the project.

\subsubsection{FACILITY OPERATIONS.}

a. Associate Project Manager for Operations and Maintenance (APMOM). The APMOM is responsible for facility systems and equipment, $Q A$, and $S$. By operating and maintaining the equipment baseline properly, existing reliability and quality assurance requirements can be met. Supporting design reviews will assist in improving quality and reliability of new or modified systems. The APMOM is responsible for operational safety.

b. Operational Safety Leader (OSL). The APMOM will be assisted by an OSL The OSL shall prepare and maintain an operational safety plan for the concurrence of the LLNL Hazards Control Office and approval by APMOM and the PM. The plan shall be included in this document and will complement as well as supplement the engineering safety work performed under the cognizance of the Associate Progrim Manager for Engineering (APME). Operations and Maintenance (O\&M) safety policies and procedures will be prepared as required for the approval and issuance of by APMOM. Operational Hazard Analyses are prepared per OSL guidance. See figure 1. 


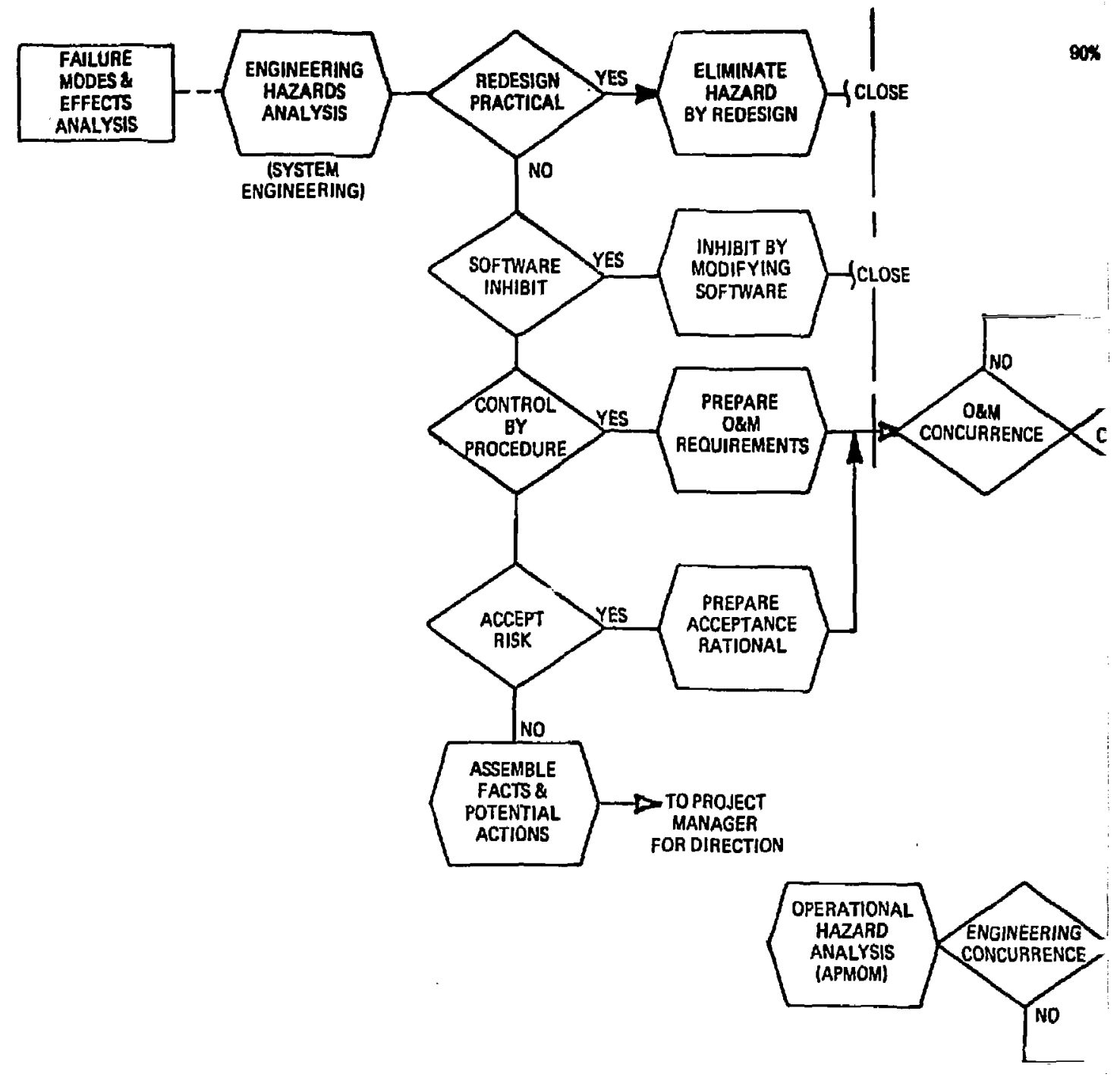

NOTE: HAZARDS RESULTING FROM SINGLE POINT FAILURE OF HARDWARE WILL BE CONSIDERED IN THE RELIABILITY RISK APPROVAL FLOW AND NOT DUPLICATED. 
90\% DESIGN REVIEW

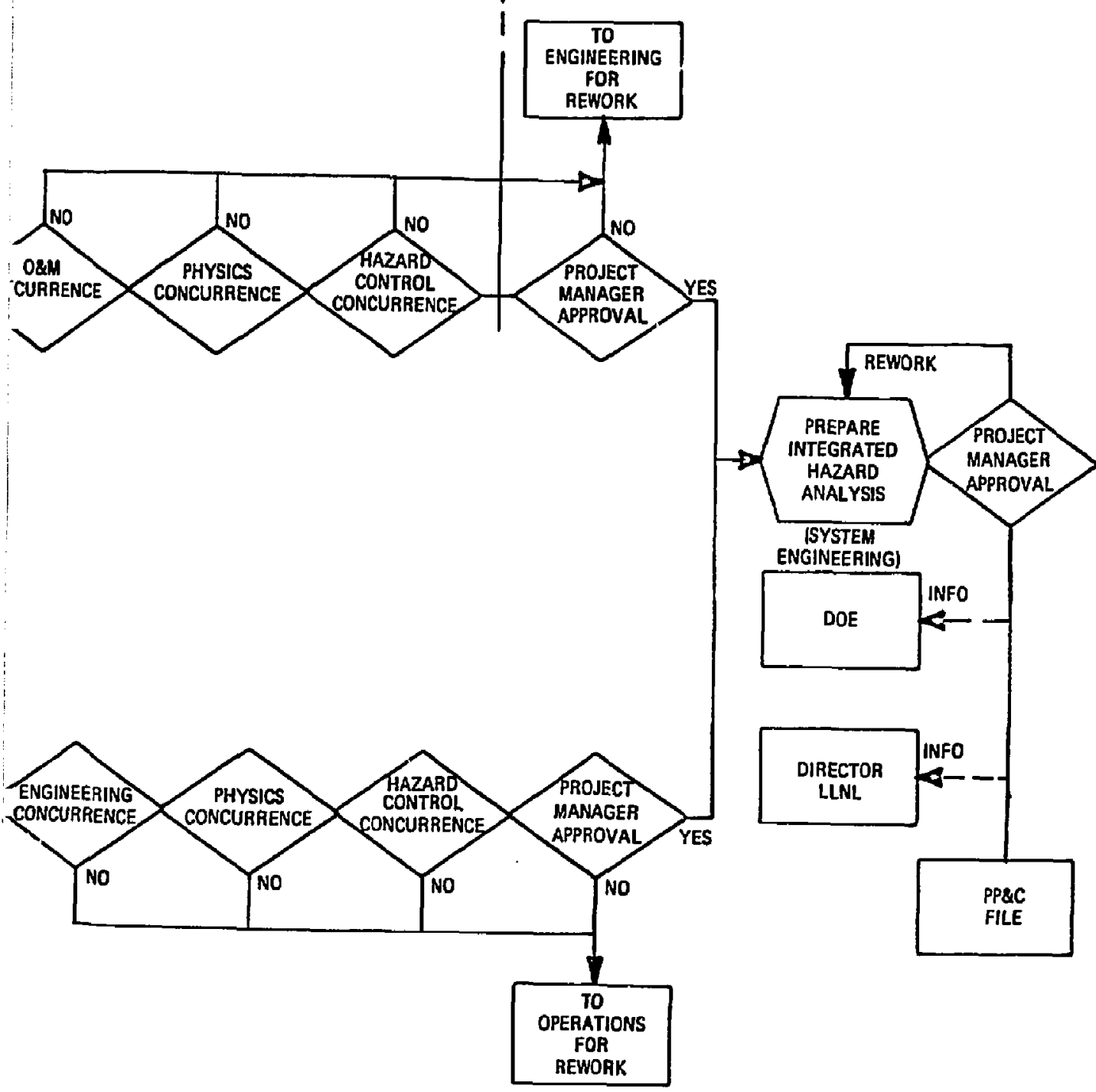

Figure 1. Hazard Analysis Acceptance Flow 


\subsubsection{ENGINEERING.}

a. APME. The APME, in conjunction with design responsibilities, executes the reliability program and engineering portion of the quality and safety prograns for the PM.

b. Lead Design Engineer. Lead design engineers are respons ible for the following $R, Q A$, and $S$ functions:

(1) Establishment of the necessary $R, O A$, and $S$ requirenents based on the systen or equipment criticality

(2) Review of single failure points, design hazards and Critical Itens List (CIL), and recommendations on improving system reliability and/or safety

(3) Review of problem reports and preparation of recurrence control response [see figure $2(C)$ ]

(4) Ensure that all critical components are qualified

(5) Establishment of requirements for traceability and limited life hardwire where needed

(6) Estabiishment of systen criteria and the preparation and use of design hazard analyses

c. System Engineering. Systen Engineering performs the following R, $M$, and $S$ functions:

(1) Assures that project $R, Q A$; and $S$ plans, policies, and procedures are properly implemented and carried out by all elements of engineering

(2) Categorizes the UTF systems and equipnent with respect to the failsafe requirement and supporting the design engineers in establishment of $R, Q A$, and $S$ requirements 


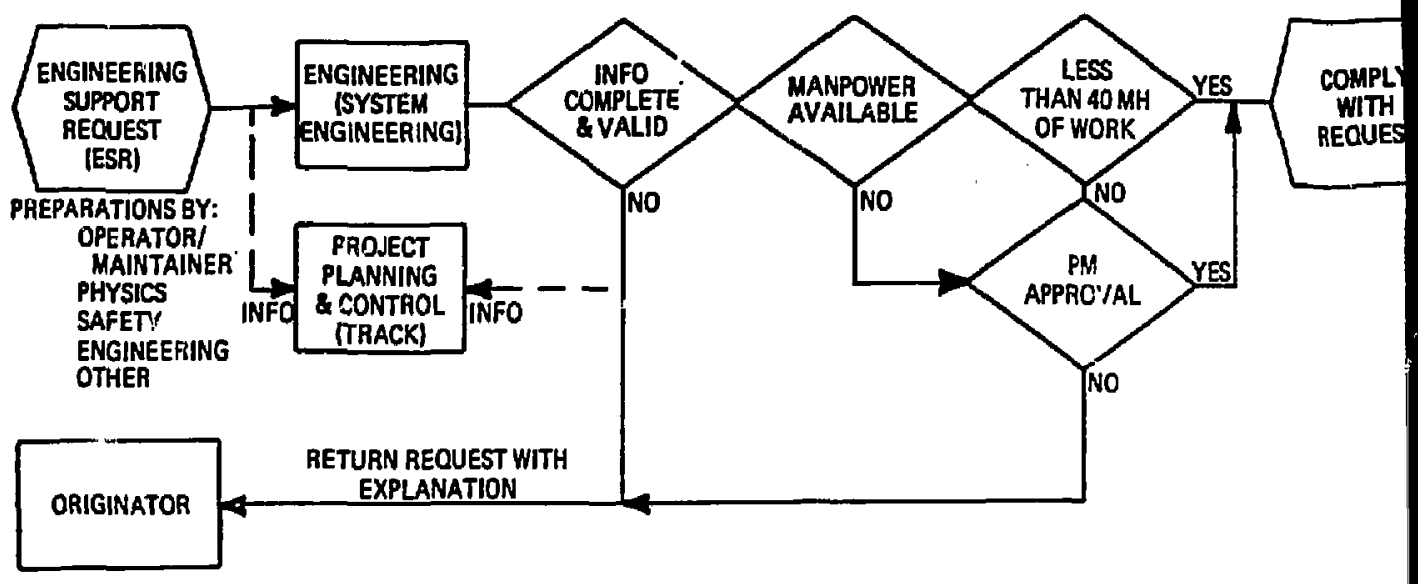

(A) GENERAL

REQUESTS FOR INVESTIGATION

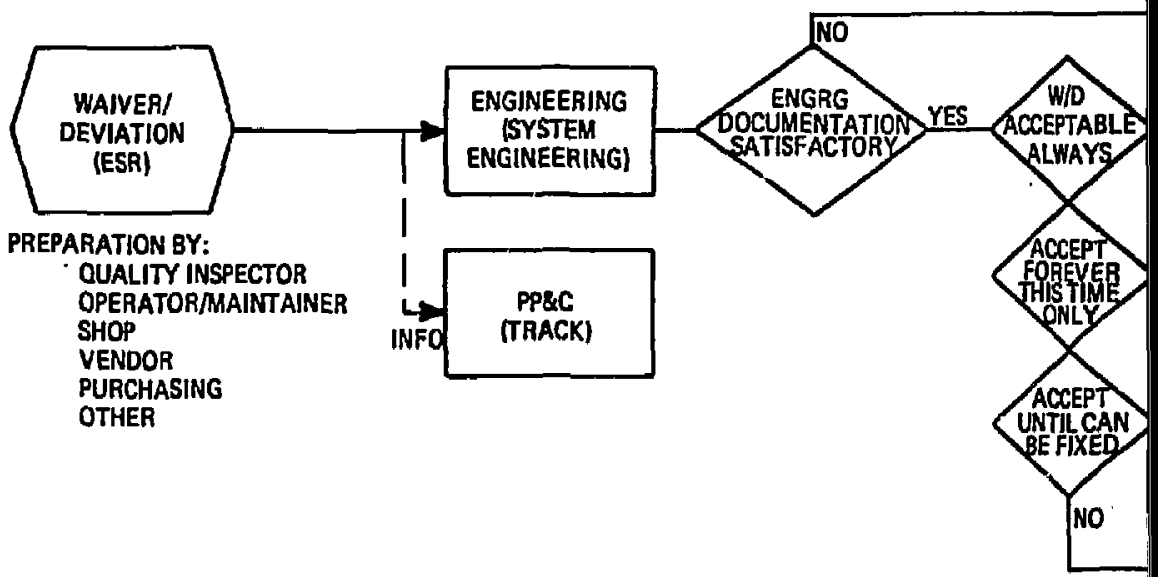

(B) WAIVER/DEVIATI 


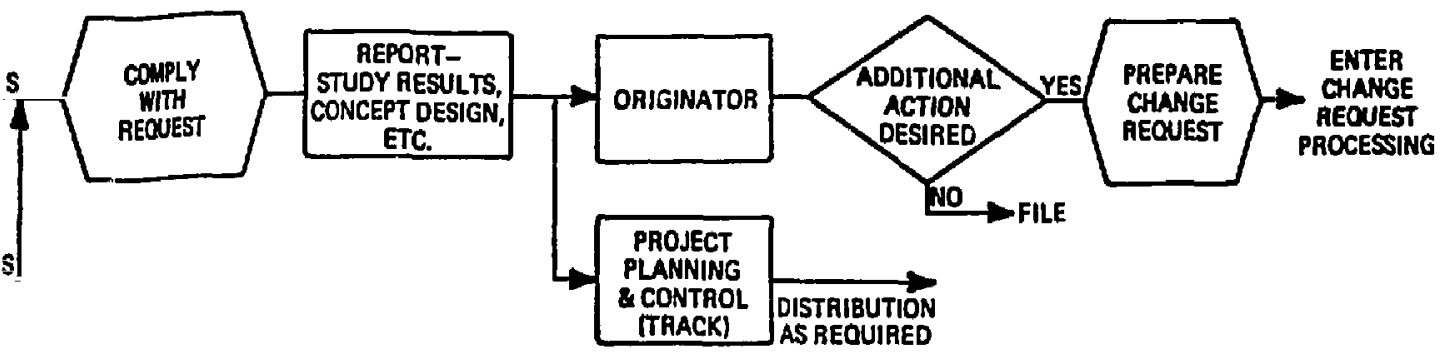

(A) GENERAL

$R$ INVESTIGATIONS AND STUDIES

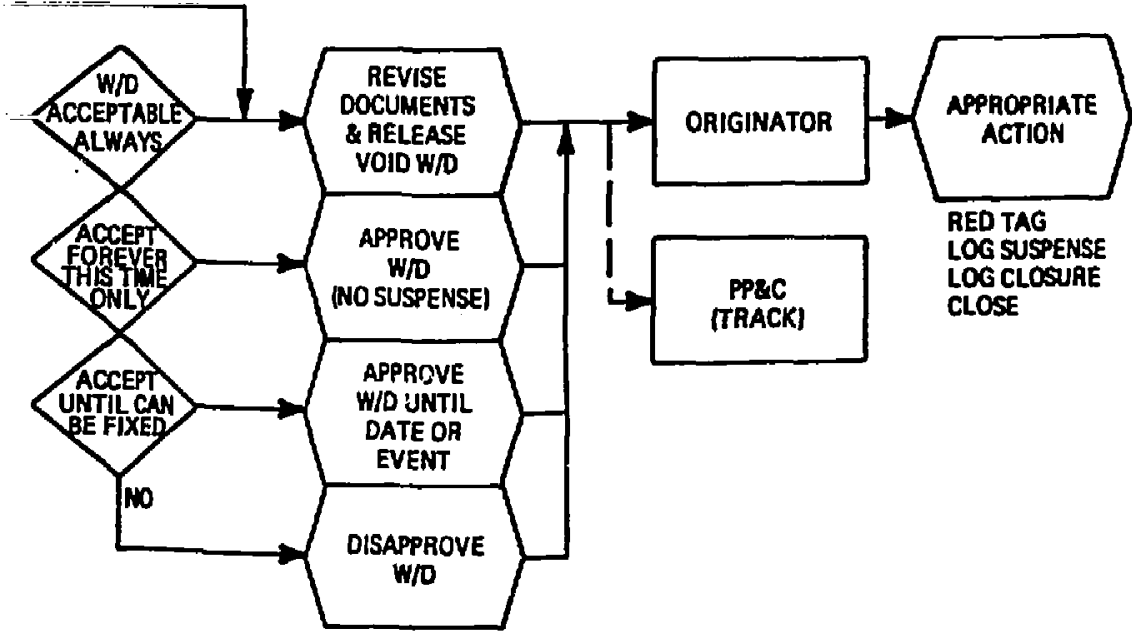

WAIVER/DEVIATIOUS

Figure 2. Engineering Support Requasts (Mo Change to Baseline) 


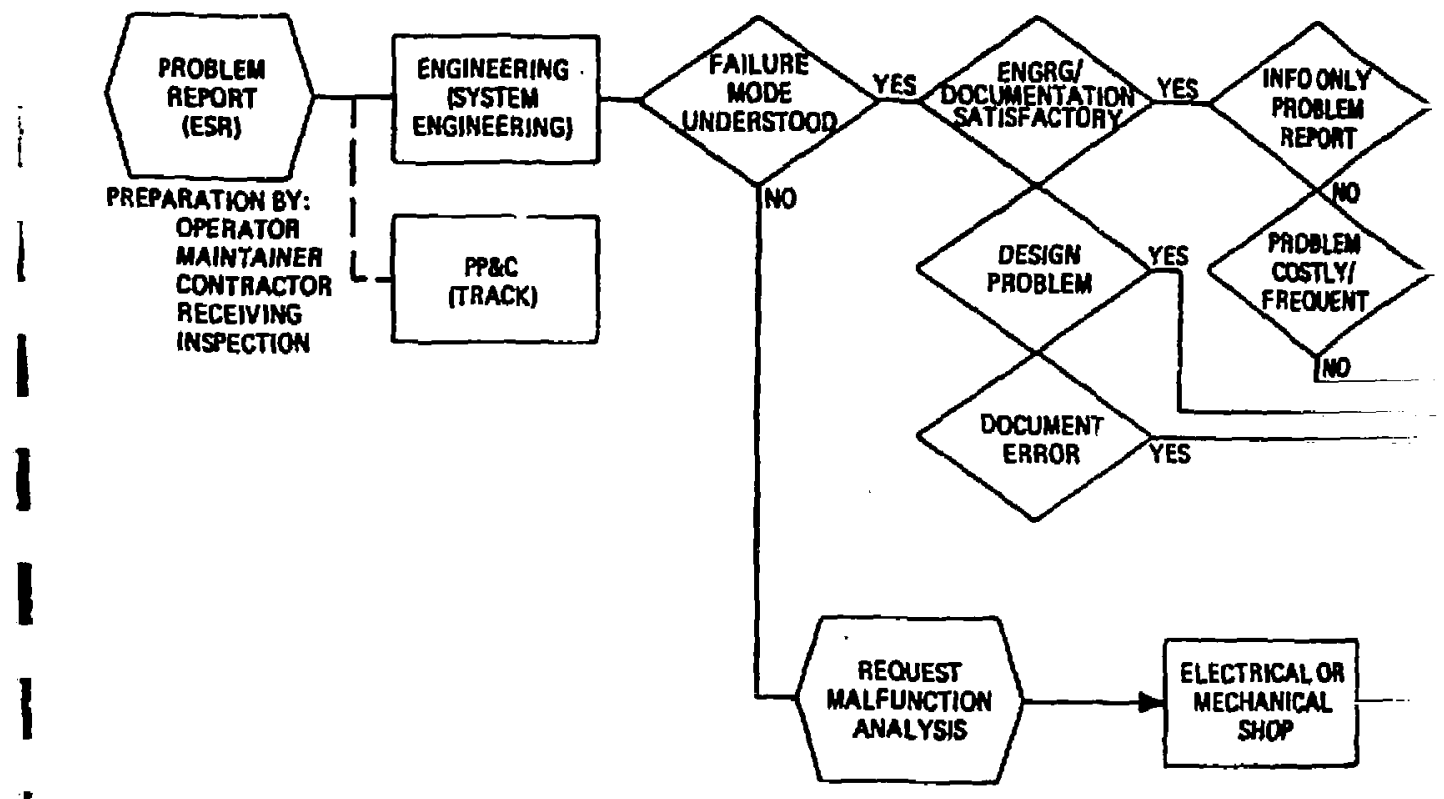

(C) PAOBLEM REPOATHW A COARE 


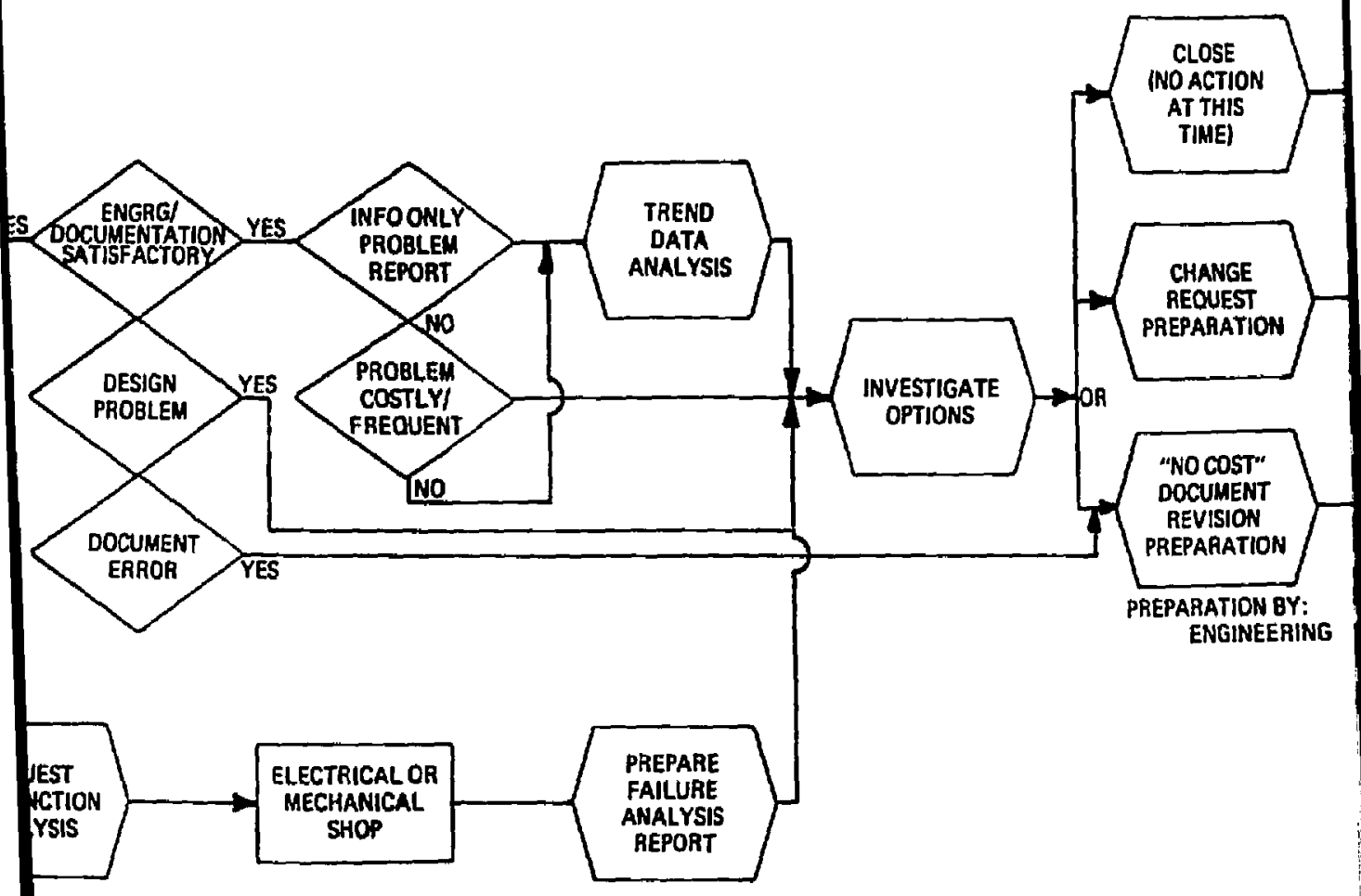

(C) PROBLEM REPOATING \& CORAECTIVE ACTION

Figure 2. Engineering Support Requests (No Change 


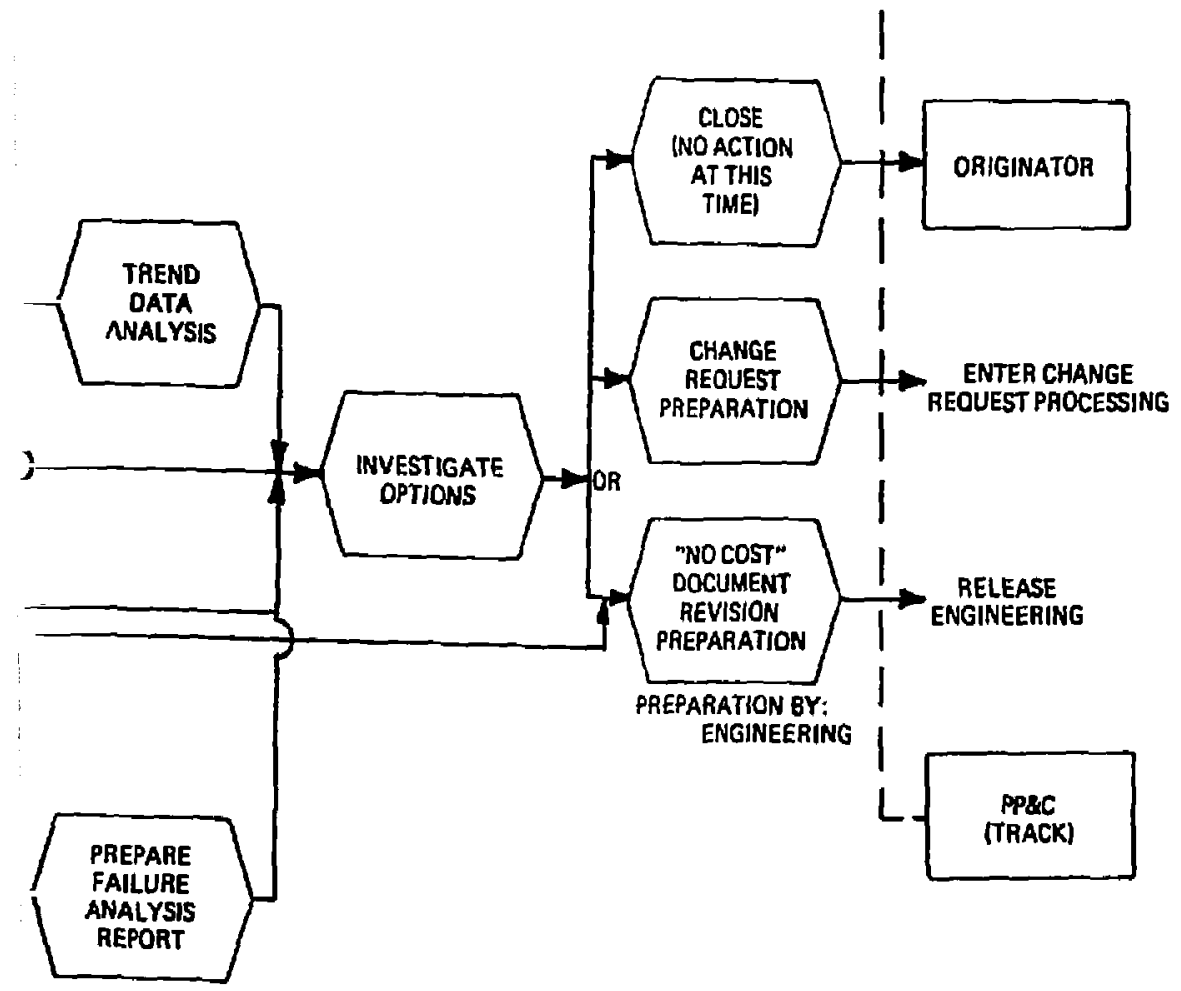

\section{SE ACTION}

Figure 2. Engineering Support Requests (No Change to Basel ine)(Cont) 
(3) Reviews engineering documentation and approves Document Release Authorization (DRA) to ensure that the appropriate provisions are included to cover the following areas:
(a) Reliability
(b) Quality
(c) Systems safety

(4) Prepares and maintains Failure Mode and Effects Analys is (FMEA) and CIL

(5) Prepares a tracking system for critical Single Failure Points (SFP's) and design hazards

(6) Initiates failure analys is requests, prepares failure analys is reports, and maintains problem trend data file [see figure 2(B)]

(7) Prepares an integrated CIL based on the individual system level and CIL's prepared by the design engineers and keeps track of changes due to design changes and reanalys is

(8) Identifies then coordinates the reviews and acceptance of critical SFP's and design hazards with the respons ible operating organization and project managenent (see figure 3 and figure 1)

(9) Reviews procurement documentation to ensure the incorporation of $R$, QA, and $S$ requirements

(10) Reviews contractor's reliability and quality assurance plans for adequacy in meeting R\&oA requirements and obtains other concurrences as required

d. Documentation for Engineering. Documentation maintains a file of all project engineering documents and the status of all actions involving engineering in $R$, $Q A$, and $S$. 
(4) FAILUAE HAZARD TO PERSONNEL OR OTHER EOUIPMENT OR DELAYS OPERATION 8 HOUAS OA MOF
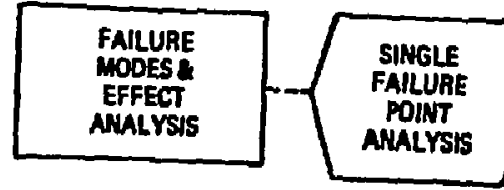

IDENTIFY

SINGLE FAILURE POINT (SFP)

(SYSTEM ENGINEERING)

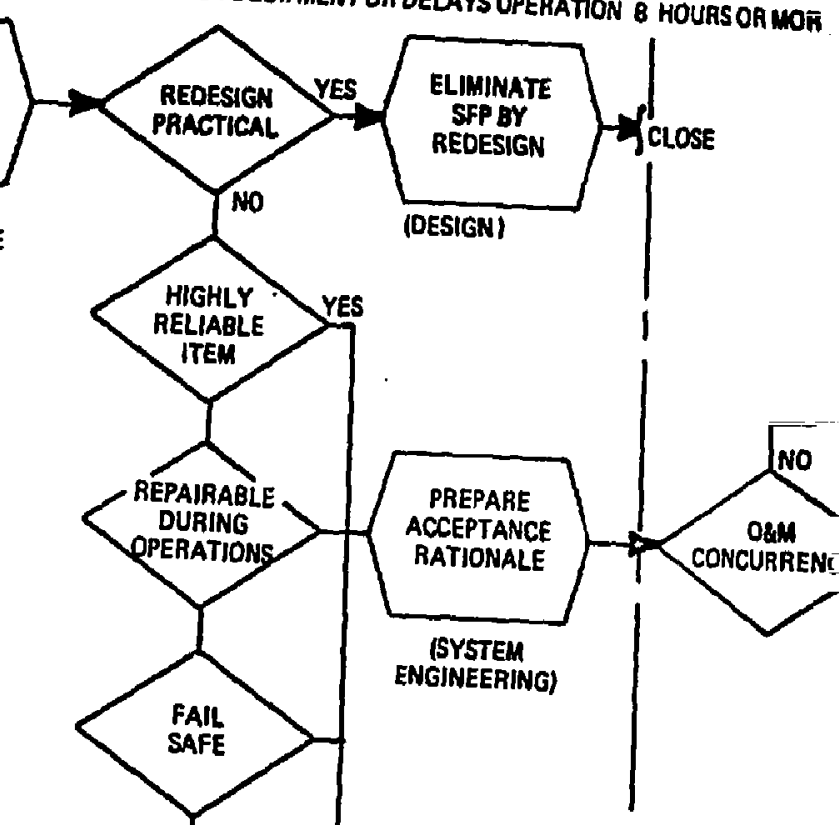

(B) FAILURE NO HAZARD TO PERSONNEL OR EQUIPMENT AND DELAY FOR REPAIR LESS THAN 8 HOURS (WIR

TOPROJECT MANAGER

FOR DIRECTION

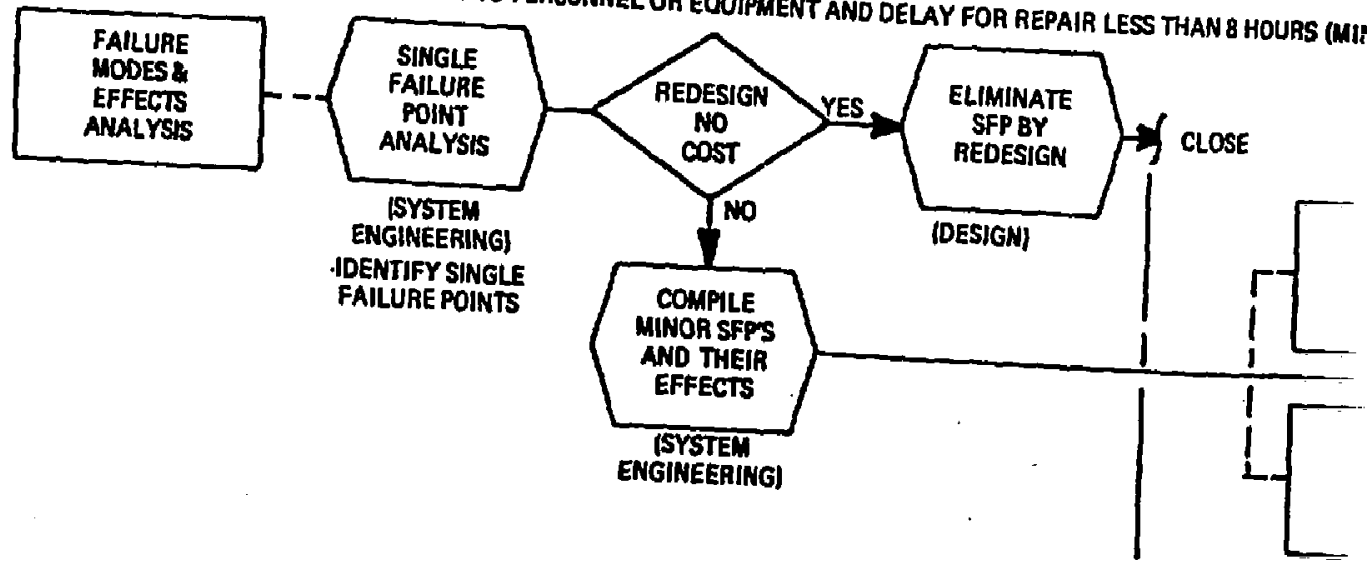




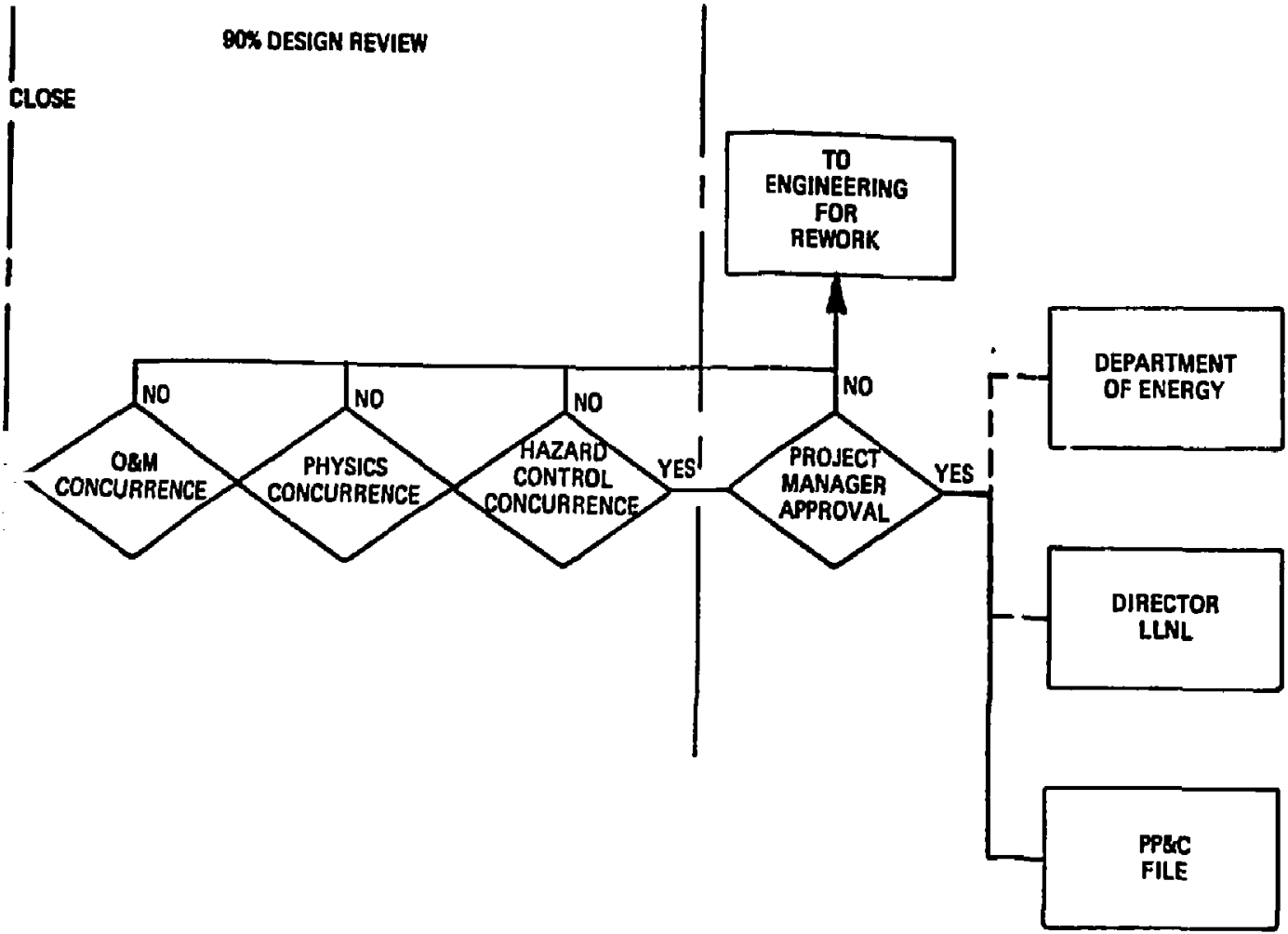

90\% DESIGN REVIEW

CLOSE

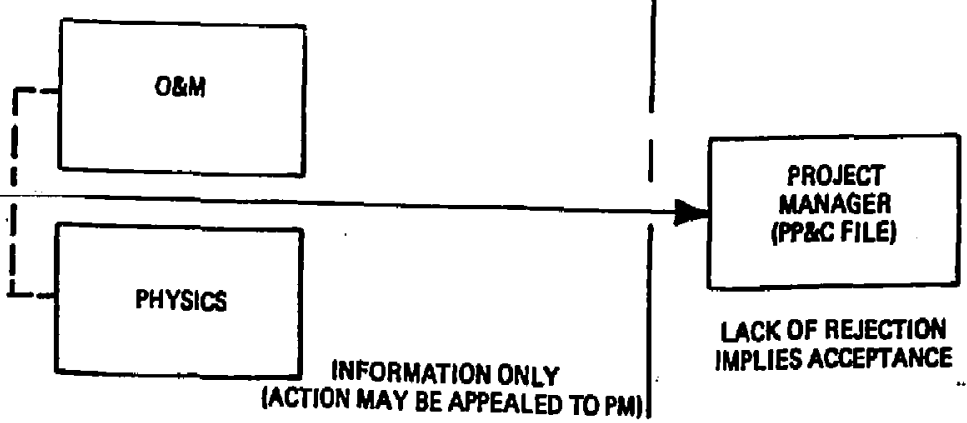


2.1.4 PHYSICS. The Associate Project Manager for Physics has little direct responsibility for $R, Q A$, or $S$. Yet his Experimentation Plan and the Experimentation Criteria are prime drivers requiring high quality and reliability. The participation of the physics experts in design reviews is necessary to achieve the most cost-effective balance of each $R, Q A$, and $S$ with practical reality.

\subsubsection{HAZARDS CONTROL. (Does not report to Project Management.)}

\subsubsection{Hazards Control Reviews and Audits. For the director of LLML, Hazards} Control Personnel will visit the MFTF- $B$ work area to assure lab standards and pract ices are being followed. Scheduled and unscheduled audits of the project will be performed at the discretion of the Hazards Control Department.

Representatives of Hazards Control will assist in design reviews change impact assessments, risk acceptance of hazards and single point failures, and operational readiness inspect ions.

\subsubsection{Hazards Control Training. The education progran of fered by the LLNL} Hazards Control Department will be utilized to instruct the necessary project personnel as to the hazards involved and the safety precautions to be taken when working with or near the MFTF-B facilities and equipment. Topics that shall be covered, as a minimum, are high voltage, vacuums, magnetism, temperatures, and pressures; microwave and high energy particle radiation; and oxygen-deficient and hydrogen-enriched atmospheres.

\subsection{TASK RESPONSIBILITIES}

The responsibilities for accomplishing the $R, Q A$, and $S$ functions contained herein are sumarized in figure 4. These functions are to be applied selectively in order to achieve the necessary levels of reliability, quality, and safety commensurate with the mission objectives and overall costs. The rationale for not accomplishing specific functions shall be provided by the responsible systems engineer.

$R, Q A$, and $S$ surveys and audits may be perfomed by any level of project management with in their area of responsibility. Scheduled surveys and audits will be formally documented. Unscheduled and random surveys and audits may be documented as minutes of meetings, memos for record, letters, or other informal documentation. An official survey and audit tile shall be maintained by each organization performing surveys and audits. 


\begin{tabular}{|c|c|c|c|c|}
\hline \multirow[b]{2}{*}{ Task Description } & \multicolumn{4}{|c|}{ Responsibility } \\
\hline & Prime & Support & Approval & $\begin{array}{c}\text { Project } \\
\text { File } \\
\end{array}$ \\
\hline $\begin{array}{l}\text { Determine Critical Systems and } \\
\text { Equipment }\end{array}$ & SE & DE & & \\
\hline $\begin{array}{l}\text { Establish } R, Q A \text {, and } S \\
\text { Requirements }\end{array}$ & DE & SE & & \\
\hline $\begin{array}{l}\text { Establish and Assure Component } \\
\text { Qualification }\end{array}$ & DE & SE & & SE \\
\hline $\begin{array}{l}\text { Establish Traceability } \\
\text { Requirements }\end{array}$ & $D E$ & SE & & SE \\
\hline $\begin{array}{l}\text { Establish Limited Life Hardware } \\
\text { Requirements }\end{array}$ & $D E$ & SE & & SE \\
\hline Conduct Design Reviews & Lead DE & SE & PM & $P P \& C$ \\
\hline $\begin{array}{l}\text { Perform Systems Assurance } \\
\text { Analys is }\end{array}$ & SE & $D E$ & PM & $P P \& C$ \\
\hline $\begin{array}{l}\text { (1) Develop Failure Modes and } \\
\text { Affects Analys is }\end{array}$ & SE & & & \\
\hline $\begin{array}{l}\text { (2) Preparation of Integrated } \\
\text { CIL }\end{array}$ & SE & & & \\
\hline $\begin{array}{l}\text { (3) Preparation of SFP with rec- } \\
\text { ommendations and rationale }\end{array}$ & SE & & & \\
\hline $\begin{array}{l}\text { (4) Component Qualification } \\
\text { Status }\end{array}$ & $\mathrm{DE}$ & SE & & \\
\hline $\begin{array}{l}\text { Coordinate Review and Acceptance } \\
\text { of SFP's and Design Hazard } \\
\text { Analyses }\end{array}$ & SE & DE & PM & $P P \& C$ \\
\hline $\begin{array}{l}\text { Nonconformance Report ing and } \\
\text { Correct ion Act ion } \\
\text { (1) Analys is of Reports } \\
\text { (2) Input ADP Progr am } \\
\text { (3) Repet it ive Problem Report } \\
\text { (Trend Analys is) }\end{array}$ & SE & DE & & EDOC \\
\hline $\begin{array}{l}\text { Failure Analys is } \\
\text { (1) In itiation of Requests } \\
\text { (2) Approval of Requests }\end{array}$ & $\begin{array}{l}\text { SE } \\
\text { O\&M, P, DE, } \\
H C, \text { SE } \\
\text { SE }\end{array}$ & DE & & SE \\
\hline $\begin{array}{l}\text { Wa iver/Devi at ions } \\
\text { (1) Prepare }\end{array}$ & $\begin{array}{l}\text { O\&M, P, SE } \\
\text { Contract ing } \\
\text { Procurement }\end{array}$ & & & \\
\hline (2) Evaluate/Concur & SE & $D E$ & APME & PP\&C \\
\hline
\end{tabular}




\begin{tabular}{|c|c|c|c|c|}
\hline \multirow[b]{2}{*}{ Task Description } & \multicolumn{4}{|c|}{ Responsibility } \\
\hline & Prime & Support & Approval & \begin{tabular}{|c} 
Project \\
file
\end{tabular} \\
\hline $\begin{array}{l}\text { Procurement Documentation } \\
\text { (1) Establish R, QA, \& S } \\
\text { Requirements } \\
\text { (2) Review and Concur in Estab- } \\
\text { lished Requirements }\end{array}$ & DE & SE & & PPBC \\
\hline $\begin{array}{l}\text { Support Requests } \\
\text { (1) Establish Quality Assurance } \\
\text { Requirements } \\
\text { (2) Review and Concur in Estab- } \\
\text { lished Requirements }\end{array}$ & DE & SE & & PP\&C \\
\hline $\begin{array}{l}\text { Establish Quality Assurance } \\
\text { Requirements }\end{array}$ & DE & SE & & PPQC \\
\hline $\begin{array}{l}\text { Perform Onsite Quality } \\
\text { Surveillance }\end{array}$ & $\begin{array}{l}\text { Organization } \\
\text { Respons ible for } \\
\text { Fabrication/ } \\
\text { Installation/ } \\
\text { Construction } \\
\text { Contract }\end{array}$ & $\begin{array}{l}\text { Other } \\
\text { Organi- } \\
\text { zat ions } \\
\text { (As Re- } \\
\text { quired) }\end{array}$ & & Prime \\
\hline $\begin{array}{l}\text { Establish System Safety Criteria } \\
\text { and Constraints }\end{array}$ & SE & $\begin{array}{l}\text { HC } \\
\text { O\&M }\end{array}$ & & \\
\hline Perform Surveys and Audits & $\begin{array}{l}\text { Any Organiza- } \\
\text { tional Element }\end{array}$ & OE & & $\begin{array}{l}\text { Any } \\
\text { Organ. }\end{array}$ \\
\hline $\begin{array}{l}\text { Maintain Tracking and Status } \\
\text { System for Single Failure Points } \\
\text { and Hazards }\end{array}$ & SE & EDOC & & PPQC \\
\hline $\begin{array}{l}\text { Perform Hazards Analys is } \\
\text { (1) Design Hazards Analysis }\end{array}$ & SE & $\begin{array}{c}\text { DE } \\
\text { Physics } \\
\text { O\&H } \\
H C\end{array}$ & PM & PPSC \\
\hline $\begin{array}{l}\text { (2) Operational Hazards } \\
\text { Analysis }\end{array}$ & ORM & $\begin{array}{l}\text { Engr. } \\
\text { Phys ics } \\
\text { HC }\end{array}$ & PM & PPSC \\
\hline (3) Integrated Hazards Analys is & SE & $\begin{array}{l}\text { Engr. } \\
\text { Phys ics } \\
\text { O\&M } \\
H C\end{array}$ & PM & PP\&C \\
\hline
\end{tabular}

Figure 4. Task Responsibilities (cont) 


\begin{tabular}{|c|c|c|c|c|}
\hline \multirow[b]{2}{*}{ Task Description } & \multicolumn{4}{|c|}{ Responsibility } \\
\hline & Prime & Support & Approval & $\begin{array}{c}\text { Project } \\
\text { File } \\
\end{array}$ \\
\hline $\begin{array}{l}\text { R, QA, and S Operating Plan } \\
\text { (Th is document) } \\
\text { (1) Reliability } \\
\text { (2) Quality Assurance } \\
\text { (a) Engineering } \\
\text { (b) Operating } \\
\text { (3) Safety } \\
\text { (a) Enqineering } \\
\text { (b) Operating }\end{array}$ & $\begin{array}{l}\text { Engineering } \\
\text { Engineering } \\
\text { Engineering } \\
\text { OsM } \\
\text { Engineering } \\
\text { OsM }\end{array}$ & $\begin{array}{c}\text { O\&M } \\
\text { Physics } \\
\text { HC } \\
\text { O\&M } \\
\text { Physics } \\
\text { O\&Ay } \\
\text { Engr. } \\
\text { OAM } \\
\text { Physics } \\
\text { HC } \\
\text { Engr. } \\
\text { Physics } \\
\text { HC }\end{array}$ & PM & PP\&C \\
\hline
\end{tabular}

Figure 4. Task Responsibilities (cont)

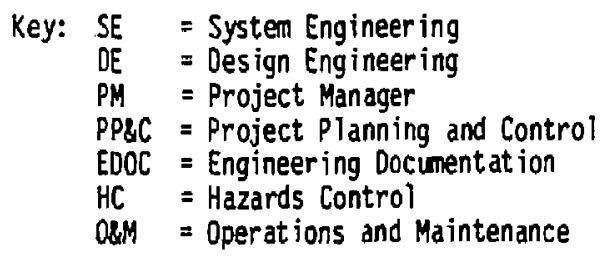




\section{ENGIYYEERING RELIABILITY AND SAFETY FUNCTIONS}

This section describes the reliability engineering functions to be performed.

\subsection{DETERAINE CRITICAL SYSTEMS AND EQUIPNENT}

a. Critical systens and equipment are defined as those systems or equipment that through operation or malfunction could cause loss of life, injury to personnel, loss of the facility, or damage to a MFTF-B system.

b. The Project systems and equipment will be analyzed to determine if they are critical. System Engineering will prepare an initial list of critical systens and equipment. The initial list will be reviewed and approved by the responsible design engineers.

\subsection{ESTABR ISH R, QA, and S REQUIREMENTS}

The design engineers will establish the necessary $R, Q A$, and $S$ requirements for each design based on the hardware complexity, supplier experience, state of hardware development, unit cost, and hardware use.

\subsection{SYSTEM ASSURANCE ANAL YSIS (SAA)}

The Reliability and Safety Analys is is fomally documented in a SAA for critical systems (see 3.1b.). An SAA consists of a brief system description, key baseline document references, FMEA, systen criticality determination, CIL, SFP (with acceptance rationale), and design hazards analysis (DHA).

SAA's required for noncritical systems will provide a brief system description, system documents reference, criticality rationale, and a design hazard analys is (see 3.3.1).

\subsubsection{FMEA AND CIL.}

a. FNEA's and CIL's will be prepared on all critical systems and equipment during the early design phase in order to provide assurance that 
unacceptable SFP's are el iminated during the design phase. FMEA's and CIL's will be used to support design reviews as required.

b. Prel iminary FMEA and CIL data will be available for the 30-, 60-, and 90-percent design reviews, as required.

c. Items appearing on the CIL will be given special attention in establishing hardware specifications and qualification requirements; in manufactur ng, inspection, and test planning; and in the formulation of operating and maintenance instructions.

3.3.2 SYSTEM SAFETY GUIDEL INES ANO CONSTRAINTS. The design engineers shall develop and establish safety guidelines, constraints, and requirements to guide the design of facilities, systems, and equiment. These criteria shall sat isfy programat ic guidelines, constraints, and systems safety goals, as well as LLNL safety requrements.

\subsubsection{DESIGN HAZARDS ANALYSIS (DHA).}

a. Hazards analys is will be performed during the early design phase in order to provide assurance that hazards are identified and resolved dur:ng the design phase where possible.

b. DHA will be used to suport the 30-, 60-, and 90-percent design reviews.

c. As a general rule, hazard analys is will be periormed on systens and equipment containing:

(1) Pressur ized vessels, tanks, lines, and similar components

(2) Hazardous fluids including cryogenics

(3) Hydraulic and/or pneumatic components

(4) High voltages, radiation sources, and associated hazardous electrical apparatus 
(5) Explosives

(6) Toyic, corrosive, and/or harmful materials or fluids

(7) Vacuum oxygen-depleted and oxygen-rich atmospheres, where personnei might enter

\subsection{PREPARATION TRACKING SYSTEM FOR CRITICAL SFP'S AND HAZARDS}

System Engineering will prepare a tracking system for critical SFP's and design hazards for their facilities, systems, and support equipment.

\subsection{COORDINATE REVIEN AND ACCEPTANCE OF SFP'S}

System Engineering will coordinate the review and approval of SFP's with the operating organizations and project management as required.

\subsection{PROBLEM REPORTING ANO CORRECTIVE ACTION SYSTEM (PRACA)}

Al1 PRACA reports (Engineering Support Request forms) received by engineering will be processed in accordance with figure $2(c)$.

\subsection{FAILURE ANALYSIS AND PROBLEM ANALYSIS}

System Engineering will request and utilize failure analysis reports and will perform problem analysis as needed.

a. A failure analysis is defined as a systematic physical investigation of hardware carried out by specially trained laboratory personnel.

b. A problem analysis is defined as a study carried out by a design organization after a failure analys is has been performed by the appropriate engineering shop. The failure andysis will form the basis of the problem analysis, but the problem analysis will be more comprehensive. 


\subsection{PROCUREMENT DOCUMENTATION}

a. The design engineer is respons ible for the preparation of the procurement documentation for initial technical procurenents.

b. Systen Engineering will assure that the appropriatic reliability requirements are included in all procurenent packages.

c. System Engineering will review all engineering procurenent requests to determine the adequacy of the specified reliability requirenents. Concurrence will je evidenced by signature.

\subsection{COMPONENT QUAL IFICATION}

Components qualified for the intended use shall be selected insofar as practical. Qualification can be by:

a. Actual testing of the component in reliability, functional, or life tests

b. Use of Goverment/Industry Data Exchange Progran (GIDEP) to obtain reliability, qualification test, and usage information on parts, material, and components

c. Satisfactory previous use data at LLNL or other reliable source

d. Where data on similar design, same materials, or same manufacturer are available, this information shall be considered.

\subsection{LIMITED LIFE HARDWARE}

d. Itens that are subject to operating time or cycle wearout will be identified by the design engineers along with required changeout schedules as part of the design documentation.

b. Age control requirements will be specified in the design documentation for those items that are subject to variations or degradation with age. 


\subsection{OESIGN REVIEHS}

a. Reliability personnel from Systen Engineering will participate in design reviens to assure that the appropriate reliability requirements are implemented.

b. Design engineers will include the FYEA and qualification testing status as part of the design review package as applicable.

\section{ENGIMEERING QLALITY ASSURANCE FUMCTIONS}

This section describes the quality assurance functions to be performed by engineering.

\section{1 quality assurance Requirements}

a. The design engineer shall establish the quality assurance requirenents necessary for procurenent, fabrication, inspection, testing, and prelaunch checkout as applicable in specifications, drawings, and procedures. The following quality assurance requirements will be considered as a minitium:

(1) Traceability requirements

(2) Identification of mandatory characteristics and mandatory inspect ion points required to verify a mandatory characterist ic

(3) Inspection and test criteria

(4) Performance and/or tolerance limits

(5) Applicable specifications for contamination control

(6) Applicable process specifications, standards, and procedures 
(7) Limited life items

(8) Acceptance/rejection criteria

b. Systen Engineering will review the design docunentation to assure that the quality assurance requirements are adequate. The ORA will be signed by System Engineering prior to design release.

\subsection{PROCUREMENT DOCUMENTATION}

a. The design engineer will assure that the appropriate quality and/or inspection requirenents are included in all procurement packages.

b. System Engineering will review all procurenent packages to determine the adequacy of the quality provisions and obtain other engineering concurrences as required. Concurrence will be evidenced by signature.

c. System Engineering will review contractor's Rtod plans for adequacy in meet ing the ReaA requirenents and obtain other concurreices as required.

\subsection{SUPPORT REQUESTS}

a. Design engineers will request inspection, as required, when preparing a request for support. When irispection is required, earh characterist ic recommended for inspection will be listed on the support request. If inspection is not requested, the organization providing support will provide routine inspection in accordance with their quality assurance plans.

b. All support requests (except requests for administrative support) will be forwarded to the responsible RacA element for review. The responsible R\&QA element will determine if the quality requirements are adequate and signed. 


\subsection{QLALITY SURVEILLANCE}

Quality surveillance is defined as the technical direction and monitoring of a contractor's quality assurance and inspection function or the quality assurance and inspection functions delegated to another agency to assure compliance with the contractual quality requirements. Engineering is responsible for the quality surveillance on all engineering contracts for construction/fabrication/ installation of facilities, systens, and equipment. For fabrication/ installation work being performed by the operations and maintenance (O\&N) organization, the O\&H organization provides the quality surveillance functions.

a. The engineering organization responsible for the management of a construction/fabrication/installation contract is also responsible for quality surveillance of the contractor.

b. The onsite quality surveillance functions may be accomplished as follows, depending on the available manpower and the skills required:

(1) MFTF personnet

(2) Other LLNL organizations

(3) Support contractors

(4) Architect/Engineer (A/E) contract for Title II services

In all of the above cases, engineering will monitor the surveillance activities for conformance to requirenents.

c. Offsite quality surveillance need will be included in the contract planning and execution.

d. The general construction/fabrication/installation quality surveillance functions to be accomplished are as follows:

(1) Review and approval of the contractor's quality assurance plans and procedures and monitor implenentation of the quality assurance program 
(2) Perform inspection of mandatory inspection points and witness contractor tests

(3) Review contractor's quality control inspection and testing records and reports

(4) Review shop drawings for quality assurance provisions

(5) Monitor the contractor's review of procurement documents and control over his subcontractors

(6) Review and monitor the contractor's receiving inspection activities

(7) Monitor the contractor's calibration procedures, methods, and schedules

(8) Monitor the contractor's failure and correct ive action system to ensure prompt and effecitive action

(9) Review the contractor's change control system and ensure that oniy authorized changes are incorporated

(10) Perform scheduled and unscheduled audits and surveys of contractors' and other agencies' quality activities

5. OPERATING QLALITY ASSURANCE FUNCTIONS

(To be completed by the APMOM)

6. OPERATING SAFETY FUNCTION

(To be ccmpleted by the OSL for the APMOH)

\subsection{OPERATIONAL HAZARDS ANALYSIS}

(To be completed by the OSL) 
APPENOIX II

INTEGRATED LOGISTICS PLAN 
MTFT-B

INTEGRATED LOGISTICS SUPPORT PLAN

TABLE OF CONTENTS

I. INTRODUCTION

\subsection{Purpose}

1.2 Objectives

1.3 Policy

1.4 Applicability

1.5 Definitions

11. ILS DEVELOPMENT PHASE

\subsection{ILS System}

2.2 Logistics Engineering Analys is

2.2.1 System Categorization

2.2.2 Critical LRU Maintainability Analys is

2.2.3 System Maintainability Analys is

2.3 Maintenance Planning and Constraint

2.3.1 Maintenance Concepts

2.3.2 General Constraints

2.3.3 Online Maintenance

2.3.4 Offline Maintenance

2.4 Operations, Maintenance, and Training Documentation Requirements

2.5 Spares Provisions and Supply Operations Requirements

2.5.1 Spare Provisioning Methodology 


\section{SECTIOH I}

INTRODUCTION

\subsection{PURPOSE}

This plan identifies the requirements, responsibilities, ground rules, and implementation guidelines for the Mirror Fusion Test Facility (MFTF-B) project integrated logisties support (ILS) activities during the operational phase of the plasma fusion experimentation activities.

\subsection{OBJECTIVES}

The primary requirenent of integrated logistics is to ensure maximum online availability of the MFTF-B systens and equipment in support of experimental operations.

The object ives of this plan include:

a. Implementation and managing the integrated logistics functions necessary for proper operation of the facility as illustrated in figure $1-1$

b. Identification and analys is of all line replaceable units (LRU's) and shop replaceable units (SRU's) for scheduled or unscheduled maintenance act ivities

c. Establishing the management controls and organization necessary to assure that all operational support activities are implemented effectively with in the budgetary and experiment schedule constraints

d. Assuring that standard and special system/component maintenance requirements are ident if ied and integrated into the facility design analys is and documentation 


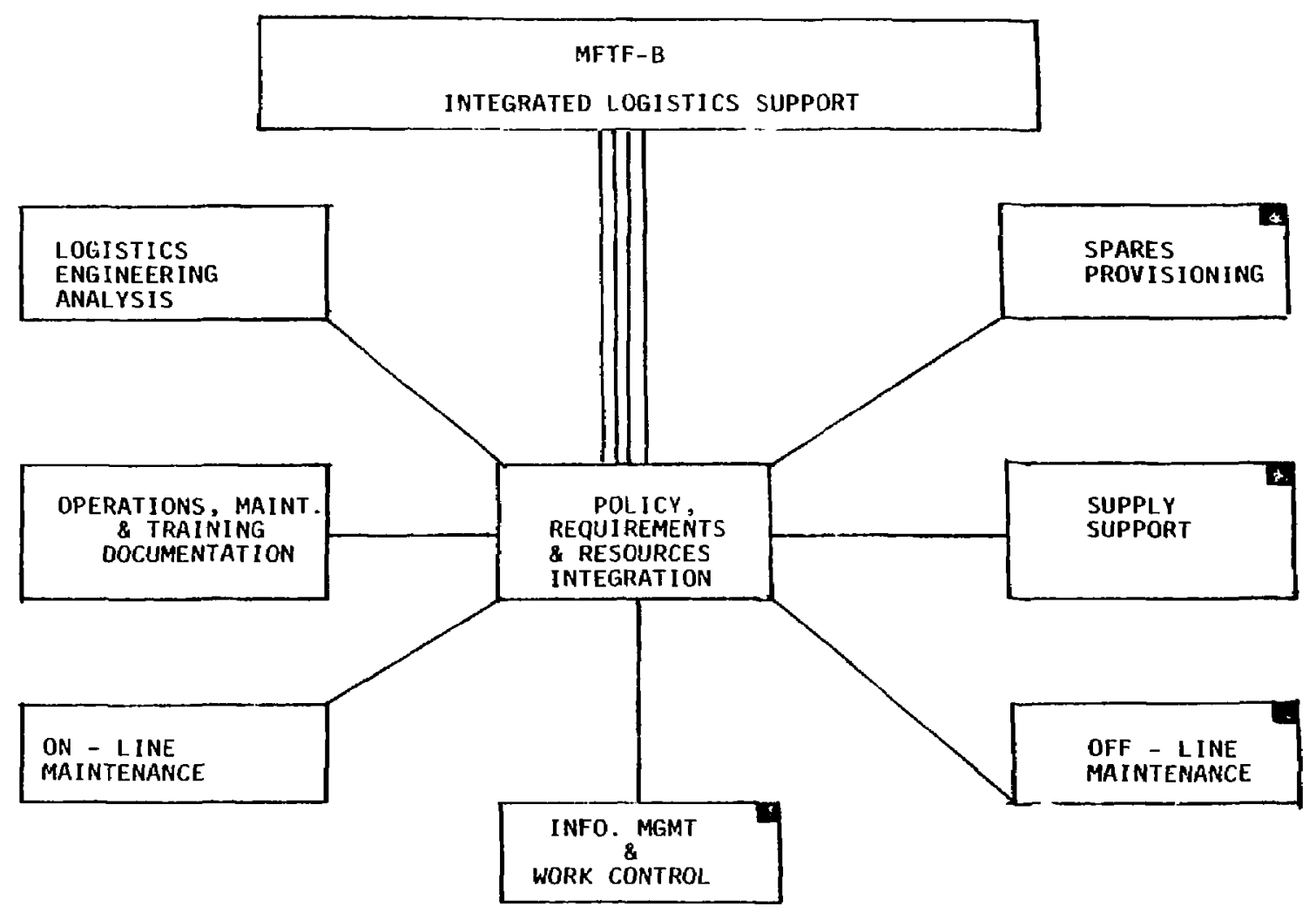

- INCLUDES NORMAL LLNL OPERATIONS SUPPORT WHERE AVAILABLE

FIGURE 1 - 1 INTEGRATED LOGISTICS SUPPORT FUNCTIONS 
e. Defining the management policy and interfaces required between the MFTF-B Project, the MFTF-B contractor( $s$ ), the Lawrence Livermore National Laboratory (LLM), the equipment vendors, and the consumable suppliers

f. Assuring that Operations and Maintenance (O\&M) documentation contracted for or prepared in-house is adequate, clearly defined, and consistent with the available operational support resources and capabilities

9. Integrating of the requirements, for LRU/SRU offline maintenance, calibration, repair, tooling, transportation, and storage with the existing and planned LLNL capabilities

h. Defining the maintainability analysis and spares analys is requirements for the hardware and consumables necessary to support the experiments

i. Eliminating all unnecessary duplication of equipment, facilities, and manpower and minimize all operational paperwork

\subsection{POLICY}

MFTF-B ILS policy is to:

a. Support the experiment schedule to the maximum extent

b. Plan and conduct hardware adjustments/replacements and preventative maintenance concurrent with operational shifts where possible

c. Establish a simple but effective systen for management, control, surveillance, and reporting of integrated iogistics activities

d. Utilize to maximum benefit the information and experience gained during similar LLIL research projects and other applicable Goverment projects 


\subsection{APPLICABILITY AND SCOPE}

This plan is applicable to all MFTF-B systems, components, support equipment, and facilities.

It is applicable to all organizations having any integrated logistics responsibility in support of the MFTF-B at LLML or at other locations such as vendor or contractor manufacturing/repair facilities.

\subsection{OEFINITIONS}

Following are definitions applicable to this plan:

a. Maintenance. Actions required to retain an iten in or restore it to a specified condition commensurate with design or test requirements

b. Item. Any level of hardware assembly (such as system, element, subsystem, equipment, component, or part)

c. Scheduled Maintenance. Any repetitive maintenance action deemed necessary to ensure functional success of equipment, including periodic servicing and replacement of time/cycle components

d. Unscheduled Maintenance. Any ma intenance activity required as a result of randam failures of equipment, including restoration to a serviceable condition of a failed subsystem, end item, replacement package, or unit, component, or part

e. Online Maintenance. Cons ists of scheduled and unscheduled actions, such as: inspection, cleaning, lubrication, servicing, calibration, adjustment, removal, and replacement of malfunctioned parts and assemblies (LRU's); in-place modif ication; in-place repair; and verification of systems, subsystems, and associated components. It is performed at the installed location of fixed itens. 
f. Offline Maintenance. Consists of scheduled and unscheduled actions, such as: repairing and verifying of LRU's removed during online maintenance; replacement or repairing of SRU's; cleaning modification, calibration, aligment, adjustment, refurbishment, and manufacture of parts; and assembly of items. It is performed in fixed facilities (shops and laboratories) onsite at LLML, at Government or comercial fixed facilities located offsite, or by dispatch of specialists with parts, materials, tools, and equipment fram these facilities to the location of an iten that requires this level of work.

g. LRU. Any item capable of being removed and replaced as an integrai un it fram a higher indenture level system or assembly at the normal online operating iocation of the item. Itens requiring more than two levels of access or extensive access time re normally not classified as LRU's.

h. SRU. Any item capable of being removed and replaced as an integral unit from a free-standing assembly or sub; "iently in a maintenancel manufacturing shop or laboratory. Nomally ssociated with itens removed from LRU's in offline shops and labs.

i. Source, Maintenance, and Recoverability (SMR) Code. A SMR code that indicates the most efficient and practical source or method of supply for selected repair parts; the maintenance facility assigned the installation or manufacture of the repair part; and recoverability aspects of the repair part. 


\section{SECTION II \\ ILS DEVELOPNERT PHASE}

\subsection{ILS SYSTEM}

The MFTF-B Integrated Logistics Support System will be structured to provide maximum utilization of the test facilities for experiment runs with minimum maintenance dountime and resource al location.

The development of the ILS system to support MFTF-B requirements will encompass the analyses and phased implementation of the following principal functions:

a. Logistics engineering analys is

b. Maintenance operations (online and offline)

c. Operations, maintenance, and training documentation

d. Spares provisioning

e. Supply support operations

f. Information management and work control

g. Policy, requirements, and resources integration

An overview of the ILS system is il lustrated in figure 2-1.

\subsection{LOGISTICS ENGIMEERING ANALYSIS}

The key element in successful integrated logistics system planning is the accurate identification and analys is of the system hardware and maintenance resource requirements in a tine frame that will permit feedback into systen design, life/cycle costing, and program budget projections. 

The MFTF-B logistics engineering analys is will proceed as follows:

a. System and equipnent categorization and LRU identification

b. Critical LRU maintainability analys is

c. System maintainability analys is

2.2.1 SYSTEM CATEGORIZATIOW. For ILS purposes, the MFTF $B$ facility will be categorized and analyzed in the system approach shown in figure $2=2$.

It must be noted that the clean separation of systens depicted herein is for logistics analysis purposes only and does not reflect the exact operational interfaces.

Group 1 and 2 systens are under the direct responsibility of the MFTF-B Project.

Group 3 systems have a shared responsibility between the MFTF-B Project and LLNL Facility Support.

Ident if ication and classification of the hardware itens for logistics engineering review shall correlate with the systems groups shown in figures 2-3 and 2-4.

Similarities of component types within different systems will be included in the analysis.

2.2.2 CRITICAL LRU MAINTAINABILITY AMALYSIS. A maintainability analys is will be performed on every LRU located within the operationally closed areas and on every critical or high value LRU ( $\$ 500$ or more) external to the vault area.

The analysis will document the information currently available from the system/ equipment manufacturers and from MFTF operating personnel on a simple checklist format as shown in figure 2-5. 
ILS MAJOR SYSTEM GROUPS

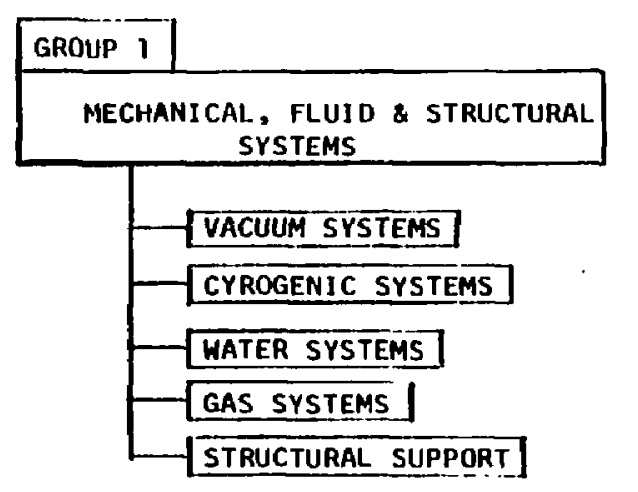

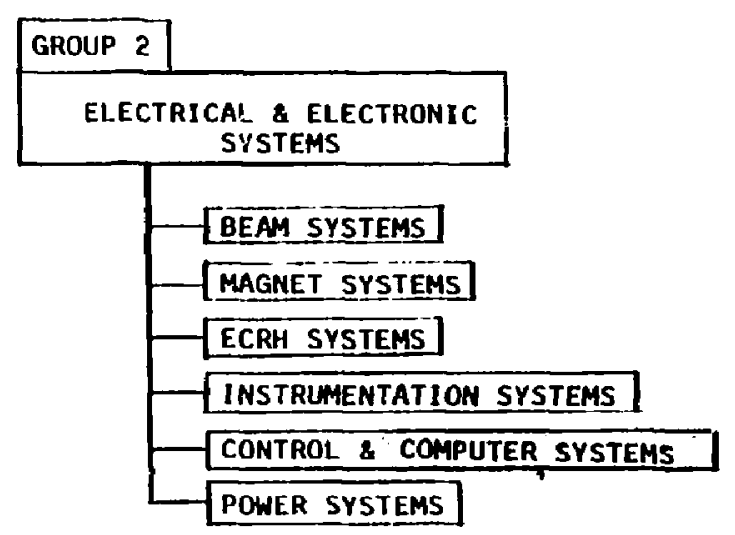




\begin{tabular}{|c|c|}
\hline $\begin{array}{l}\text { AACUIM } \\
\text { SYSTEMS }\end{array}$ & \\
\hline \multicolumn{2}{|c|}{$\begin{array}{l}\text { VACUUM } \\
\text { VESSEL }\end{array}$} \\
\hline \multicolumn{2}{|c|}{ | CYROPANELS } \\
\hline \multicolumn{2}{|c|}{$\begin{array}{l}\text { THERMAL } \\
\text { ABSORBERS }\end{array}$} \\
\hline \multicolumn{2}{|c|}{$\begin{array}{l}\text { INJECTOR } \\
\text { ACCESSORIES }\end{array}$} \\
\hline \multicolumn{2}{|c|}{$\begin{array}{l}\text { BEAMLINE } \\
\text { ENCLOSURES }\end{array}$} \\
\hline \multicolumn{2}{|c|}{ GETTERS } \\
\hline \multicolumn{2}{|c|}{$\begin{array}{l}\text { SUBL IMATION } \\
\text { PUMP }\end{array}$} \\
\hline \multicolumn{2}{|c|}{$\begin{array}{l}\text { EXTERNAL } \\
\text { VACUUM SYSTEM }\end{array}$} \\
\hline \multicolumn{2}{|c|}{$\begin{array}{l}\text { ROUGH } \\
\text { VACUUM SYS. }\end{array}$} \\
\hline \multicolumn{2}{|c|}{$\begin{array}{l}\text { HIGH } \\
\text { VACUUM SYS. }\end{array}$} \\
\hline \multicolumn{2}{|c|}{$\begin{array}{l}\text { LOCAL CONTR } \\
\text { MONIIOR }\end{array}$} \\
\hline & $\begin{array}{l}\text { UXILIARY } \\
\text { YSTEMS }\end{array}$ \\
\hline
\end{tabular}

\begin{tabular}{|c|c|}
\hline $\begin{array}{l}\text { CRYOGENIC } \\
\text { SYSTEMS }\end{array}$ & \\
\hline \multicolumn{2}{|l|}{ HELIUM } \\
\hline \multicolumn{2}{|c|}{$\begin{array}{l}\text { LIQUIFICATI ON } \\
\text { /REFRIG. }\end{array}$} \\
\hline \multicolumn{2}{|c|}{ RECOVERY } \\
\hline \multicolumn{2}{|c|}{ STORAGE } \\
\hline \multicolumn{2}{|c|}{ DISTRIBUTION } \\
\hline \multicolumn{2}{|c|}{$\begin{array}{l}\text { MAGNET } \\
\text { GUARD VAC. }\end{array}$} \\
\hline \multicolumn{2}{|c|}{$\begin{array}{l}\text { LOCAL CONTR. } \\
\text { \& MONI TOR }\end{array}$} \\
\hline \multicolumn{2}{|l|}{ NITROGEN } \\
\hline \multicolumn{2}{|c|}{ REL IQUI F IER } \\
\hline \multicolumn{2}{|c|}{ LN2 STORAGE } \\
\hline \multicolumn{2}{|c|}{ LN2 DISTRIB. } \\
\hline \multicolumn{2}{|c|}{$\begin{array}{l}\text { CYRO } \\
\text { AUXIL. SYS. }\end{array}$} \\
\hline $\begin{array}{l}\text { LOCAL } \\
\& \text { MONI }\end{array}$ & $\begin{array}{l}\text { CONTR. } \\
\text { TOR }\end{array}$ \\
\hline
\end{tabular}

WATER
SYSTEMS

\begin{tabular}{|l|}
\hline ICHS \\
\hline $\begin{array}{l}\text { PLASMA } \\
\text { DUMPS }\end{array}$ \\
\hline $\begin{array}{l}\text { MAGNET } \\
\text { LINERS }\end{array}$ \\
\hline
\end{tabular}

HPWCS

LCW
GAS

SYSTEMS

\begin{tabular}{|l|}
\hline DEUTERIUM \\
\hline $\begin{array}{l}\text { PLASMA } \\
\text { STREAMING }\end{array}$ \\
\hline $\begin{array}{l}\text { MEUTRAL } \\
\text { BEAMS }\end{array}$ \\
\hline $\begin{array}{l}\text { GAS BOXES } \\
\text { /BLANKETS }\end{array}$ \\
\hline DIAGMOSTICS \\
\hline
\end{tabular}

ARGON

GN2

GHE

COMPRESSED AIR
STRUCTURAL

SUPPORT

EQU I PMENT

\begin{tabular}{|c|}
\hline $\begin{array}{l}\text { HANOL ING } \\
\text { \& ACCESS }\end{array}$ \\
\hline $\begin{array}{l}\text { TEST } \\
\text { STANDS } \\
\end{array}$ \\
\hline $\begin{array}{l}\text { SUPPORT } \\
\text { FIXTURES }\end{array}$ \\
\hline $\begin{array}{l}\text { STORAGE \& } \\
\text { SHIPPING } \\
\text { CONTAINERS }\end{array}$ \\
\hline
\end{tabular}

FIGURE 2-3. GROUP I SYSTEM/SUB-SYSTEMS 
GROUP 2 - ELECTRICAL \& ELECTROHIC

ILS SYSTEN / SUE-SYSTEM DEFIMITION

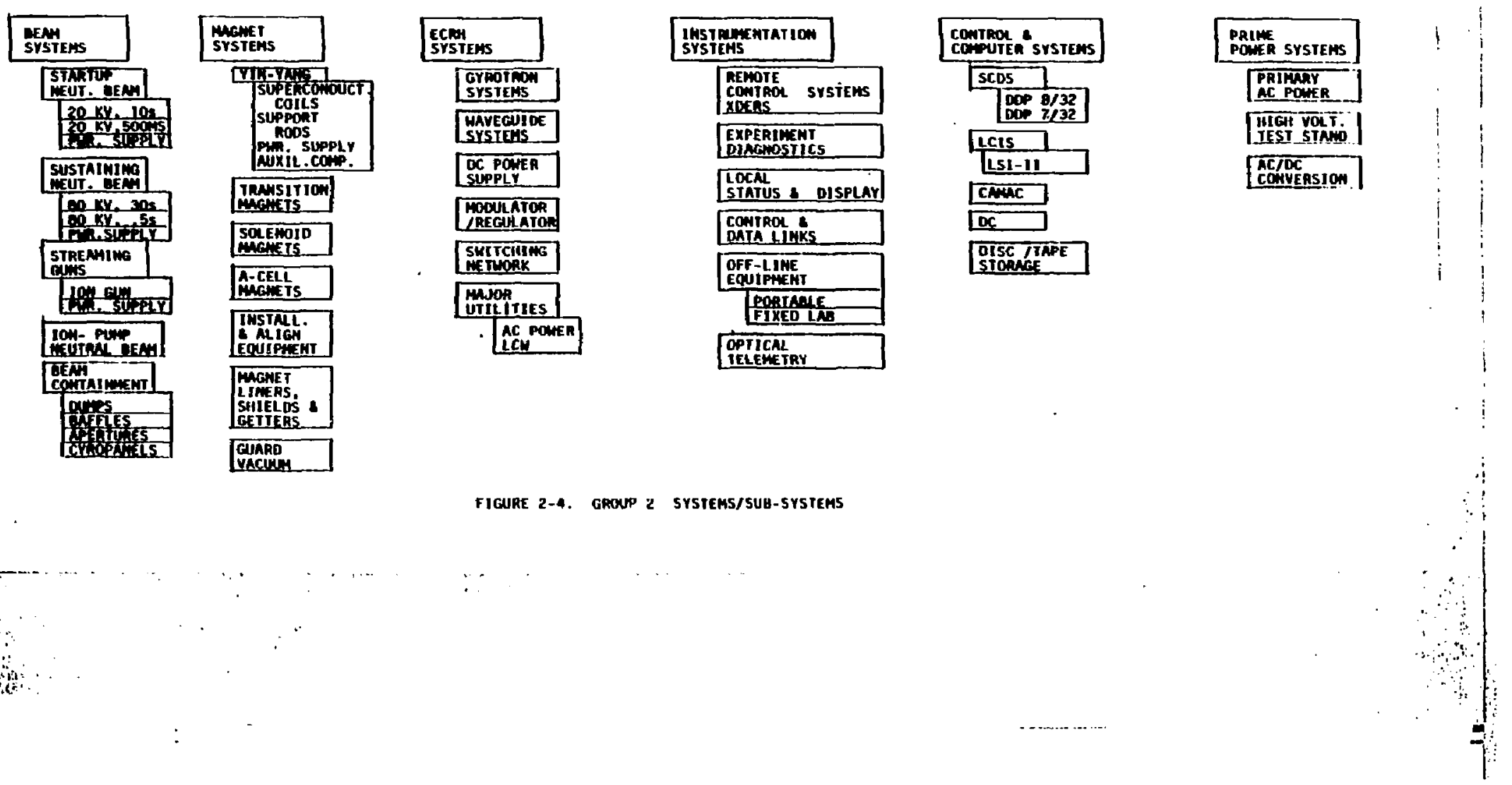




\section{LRU MAINTAINABILITY ANALYSIS CHECKLIST}

\section{MURROR FUSION TEST FACIUTY}

ORIGINATOR

LFU NAME

SYSTEM NAHE
DATE

LRU PART NO.

SYSTEM DESIGNATORMES NO.

LRU NEXT HIGHEA ASSY DHG NOISI.

MES NO.

LAU PRICE $\mathbf{s}$

SYSTEM

CONTRACTOR<smiles>CC[W]=O</smiles>

OBTAINABLE FROM:

TOTAL OTY IN SYSTEM

OEM P/N

MTBF HRS

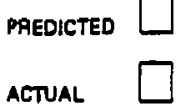

MTTR HRS

PREDICTED
NOAMAL FAILURE MODES

REPAIR PAFTS HEQUIRED: YES

SOFT GOODS REQUIRED: YES

LRU LOCATION: INTERNALTO

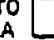

VA

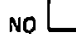

No $L$

EXTERNAL TO

LRU CAITICALITY: MANDATORY $\square$ NOMMANDATORY $\square$

LRU SERVICING

REOUIREMENTS:

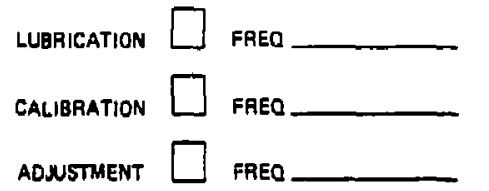

\section{REPAIR}

PARTS P/N

SOFT

GOODS PN PRICE 5 PRICE $\$$
LRU REPAIRAELE: YES $\square$ NO $\square$

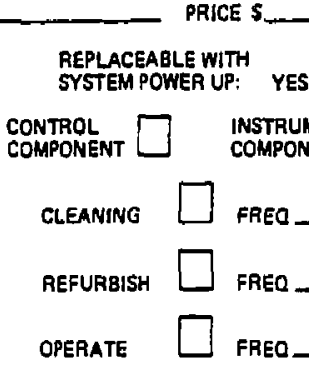

LRU AGETIMEICYCLESSHELF REQUIREMENTS:

ACCESSTO

NO $\square$ DIRECT ACCESS $\square$.

2ND LEVEL $\square$ 3AD LEVEL

TIME

LAU REQUIAEO: YES $L$

MAGNETIC FIELD $\square$

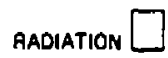

VOLTAGE $\square$

REOUIRED

SAFETY CONSIDERATIONS

TEAPERATURE

WEIGHT/SIZE

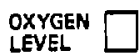

PAEssuae

LEVEL

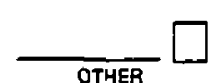

LRU REMOVAL:

TIME REQUIRED REMARKS

LRU INSTALLATION: TIME REQUIRED REMARKS

TOOLSIFIXTURES AEOUIRED:

\section{STANDARD} TOOLS

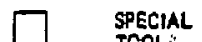
TCOL

SPECIAL TOOLS FIXTURES P/N

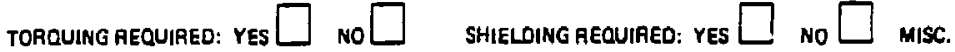

LAU AONUTTMENT $\square$ LRU RETEST AFTER INSTALLATION: YES $\square$ NO $\square$ REQUIFED__AFTER INSTALLATION: YES $\square$ NO $\square$ REQUIREO TEST EOUIPMENT REQUIAED: STANDARD 
Each LRU analys is will address in particular the following cons iderations:

a. LRU access and removal/installation time

b. LRU servicing, lubrication, and time/cycle requirements

c. Repair capability and recomended repair parts, materials, and soft goods

d. Test/calibration ecuipment and tooling not currently available at LLNL

\subsubsection{SYSTEM MAINTAINABILITY ANALYSIS. Integration of the individual LRU} analyses with the system maintainability goals will establish the minimum online and offline maintenance requirements in support of the experiment operations. The system analys is will be documented as follows:

a. Preliminary on line maintenance matrix chart(s)

b. Preliminary of fline repair assignments and schedules

c. Addition of repair item costs to the spares budget projection

d. Addition of test equipment and tooling costs to the capital equipment budget protection

e. MFTF-B manpower projections to support online and of $f$ line maintenance operations

\section{3 maintenANCE PLANNING ANo CONSTRAints}

\subsubsection{MAINT:ENANCE CONCEPTS. The MFTF-B operational exper iment schedules} require that online and of 1 line maintenance activities be marlaged and integrated in a joint effort directed at maximum compliance with experiment support.

Maintenance olanning will meet the primary goals outlined in the ma intenance concepts shown in figures $2-6$ and $2-7$. 


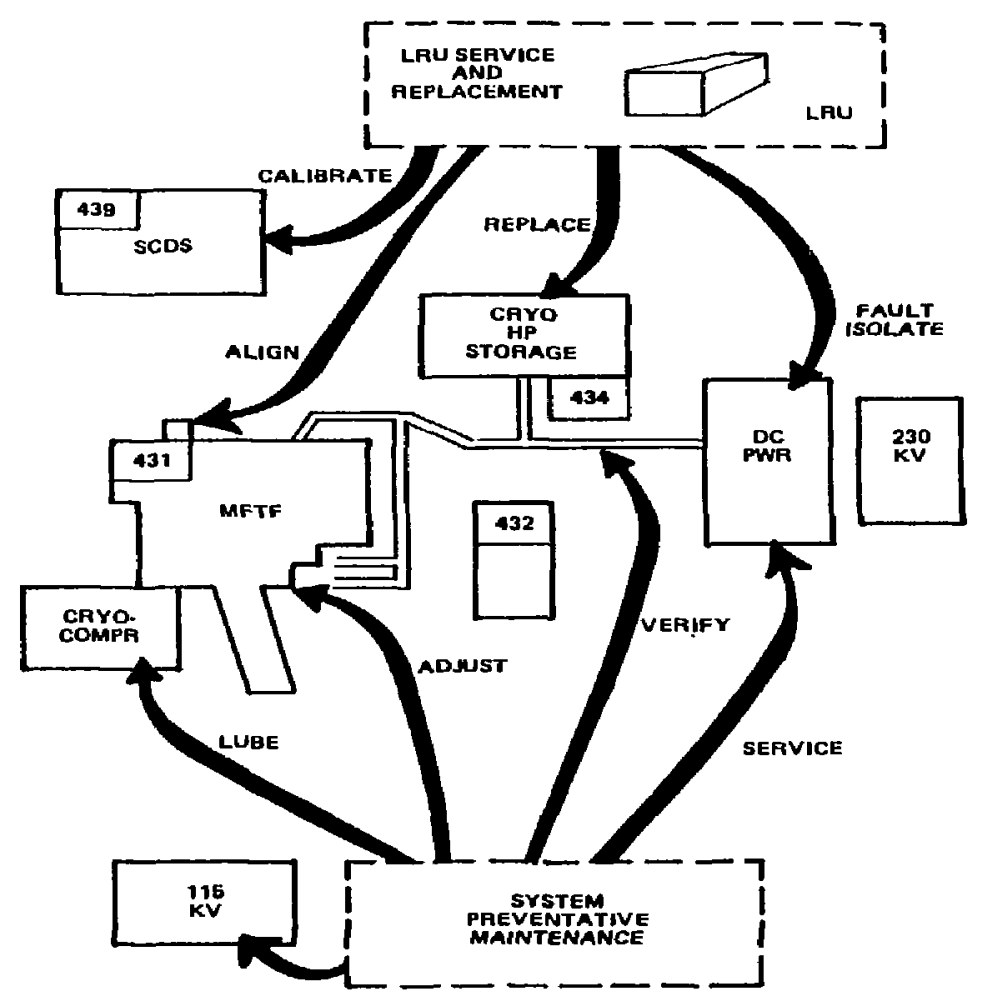

Figure 2-6. Online Maintenance Concepts 


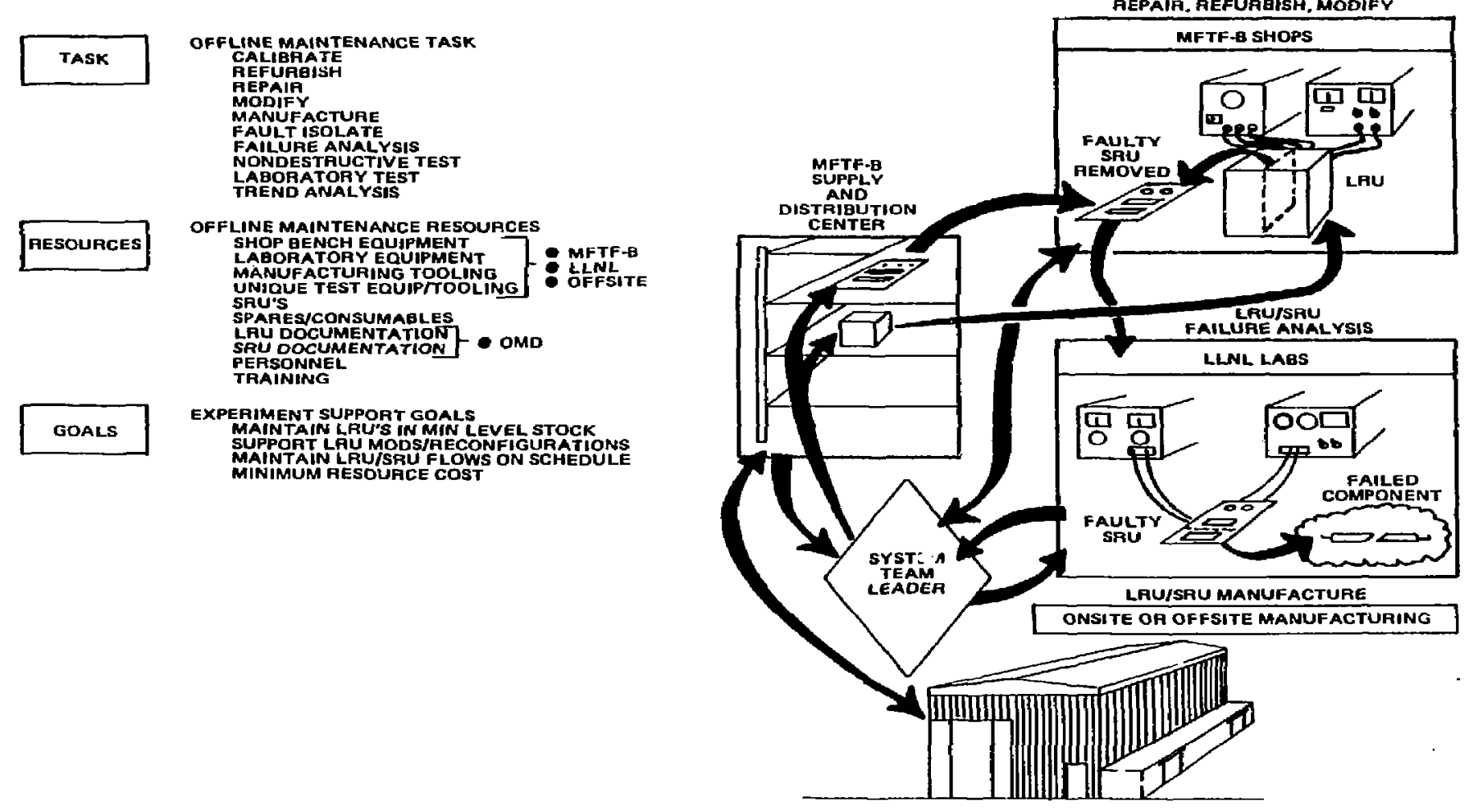


The System Maintainability Analysis will provide the prime data source for integrated maintenance planning.

2.3.2 GENERAL CONSTRAINTS. The MFTF-B maintenance plan will take into account:

a. Existing onsite maintenance capability. Use of existing and/or modified resources will be emphasized.

b. Limited manpower/equipment resources and spares

c. LRU and SRU changes due to experiment results or reconf igurations

d. Average turnaround time for repairable LRU's to be recycled will be 15 days for MFTF-B project repair, 30 days for assigned LLNL lab repair, and 90 days (including shipping) for of fsite repair.

e. Incremental maintenance funding and equipment acquisition during installation and test phase to insure full capability by the operational date

2.3.3 ONLINE MAINTENANCE. On line maintenance planning will cover three bas ic areas of operations:

a. Preventive/correct ive maintenance

b. LRU replacement

c. Equipment reconf igur ation/instal lation

2.3.3.1 Preventive/Corrective Maintenance. Preventive/corrective ma intenance for MFTF-B systems will consist of all scheduled or unscheduled activities required to maintain operational equipment in ready condition for experiment support, including in-place calibrations, adjustments, or alignments.

2.3.3.2 LRU Replacement. LRU replacement will include replacement for (1) preventive/corrective maintenance reason such as lab calibrations, filter replacements, time/cycle/age changeout or (2) hard failure or suspect failure. 


\subsubsection{Equipment Reconfiguration/Installation. Equipment reconfiguration/}

installation will consist of those activities associated with the reconfiguration of the experiment system( $s$ ) or the installation of new or modified equipment to support new experiment requirements.

\subsubsection{Online Experiment Support Analysis. The minimum onl ine maintenance} requirements defined in the system maintainability analys is will be integrated with the total experiment support scisdules and will include evaluation of:

a. Personnel requirements and saiety re ictions

b. Envi rorment/c leanli iness requirements

c. Special support (e.g., cranes, forklifts, etc.)

d. Verification, alignment, and retest times

2.3.3.5 Online Matrix Chart. The prel iminary online maintenance matrix will be finalized by including estimates for failed LRU replacement activities, estimates for equipment reconfiguration activities, and the results of the above onl ine experiment support analys is.

2.3.3.6 Online Scheduling. The online maintenance matrix will be utilized for management visibility and maintenace scheduling control.

The matrix will be a dymamic control vehicle and will require inputs from each of the affected system team lead technicians on a continuing bas is to reflect actual operating experience. The matrix will be formally revised monthly during the first 4 months of system operation and quarterly (as required) thereafter.

2.3.3.7 New/Modified Design Impact. Impact on online ma intenance operations will be evaluated during the analys is of any requested new design effort.

2.3.4 OFFLiNE MAINTENAMCE. Offline maintenance planning will cover two bas ic areas of operations:

a. LRU/SR!! ma intenance flow

b. Shop/Lab $(S / L)$ pracess control 
2.3.4.1 LRU/SRU Maintenance Flow. Removal of an LRU from operat ion and induction into the offline cycle intitiates a maintenance flow, completed upon return of a repaired/refurbished LRU to inventory. LRU flaw will be controlled by the system team responsible for the particular LRU. Status and tracking of the LRU flow will be maintained by the MFTF-B Supply and Distribution Center (S8DC) for system team and management visibility.

\subsection{Scheduled offline Maintenance Flow. Basic flow necessary to perform} offline maintenance for an LRU/SRU removed for scheduled maintenance is show in figure 2-8. An LRU removed during online maintenance is routed per system team leader direction. The LRU may be routed directly to a prime $S / L$ for repair or refurbisment or to the MFTF-B SLDC for shipping to an offsite agency. The team leader will utilize the LLML transportation services as required for hardware handling and delivery. In all cases, the S\&DC shall be not if ied of the LRU status and schedule. The work order (see figure 2-9) accompanying the LRU will be used by the $S / L$ work control for planning, scheduling, and production control information.

The LRU initially will be scheduled for maintenance or service to the lowest part level required. An inspection will be conducted to determine the extent of wear and tear for time/cycle components. Any parts, components, or SRU's requiring maintenance or service will be removed from the LRU in accordance with applicable maintenance instructions and documentation. If, during testing, a problem or anomaly is discovered, a problem report will be written and dispositioned and a copy attached to the work order [see Reliability, Quality Assurance, and Safety Plan, appendix I, figure 2(c)].

Upon completion of testing, required maintenance or service will be identified and documented. This will include any work required on SRU's or other removed parts. Parts or SRU's that require cleaning or other service exceeding the capability of the prime $S / L$ will be sent to a designated $S / L$ accompanied by necessary routing and disposition instructions. Once support work is completed, SRU's either can be returned via S\&DC to stock or sent to the proper S/L for reassembly into serviceable LRU'S. 


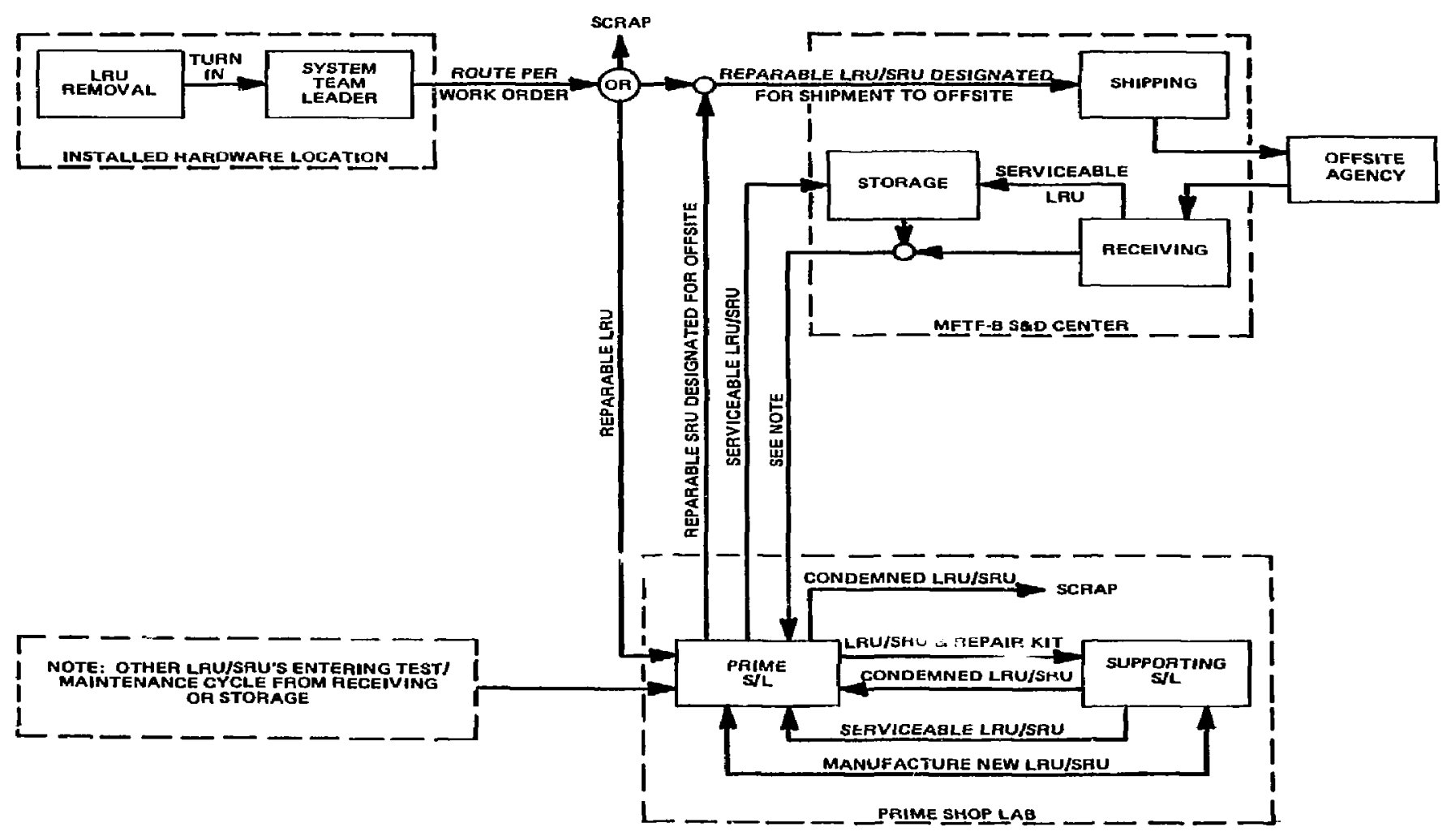

Figure 2-8. Scheduled Removal Line Replaceable Unit Maintenance Flow 
MFTF-B

OSM

WORK ORDER

\section{DATE}

PART NO. TITLE WORK OROER NO.

SYSTEM WBS NO. REQUESTOR

$\mathrm{JOB}$ CONTACT

DUE DATE EST. HRS.

ORAWING/PROCEDURE NO. HARDWARE FAILURE - ACTUAL SUSPECTED JOB DESCRIPTION:

\& ROUTING INSTRUCTIONS:

RETURN TO REQUESTOR $\square$

RETURN TO S\&OC $\square$

AUTHORIZED BY:

DO NOT WRITE BELOW LINE, SHOP USE

ASSIGNED TO JOB NO.

ESTIMATE Start

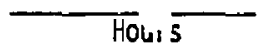
Comp

DATE COMP QA DATE NOTES 
Accepted LRU'S/SRU's are returned to the requestor or turned in to the \$\&DC for receipt, accountability, and routing to the appropriate storage area for that item. Entries of completion and inspection will be made on the work order and forwarded with the LRU.

As shown in figure 2-8, a removed LRU may be designated to be sent offsite. LRU's in this category will be transported to the S\&OC for packaging and shipping. If a problem, failure, or other anomaly is discovered during testing at an offsite location, a problem report will be written and forwarded to MFTF. Once the LRU is repaired and shipped back to central supply, it can be routed either to a designated $S / L$ for validation or returned directly to storage, depending on acceptance requirements.

Similarly, LRU's or SRU's in storage periodically can be sent to a designated $S / L$ for reverification per shelf and storage life requirements and then returned to storage. Finally, if a removed LRU is coded as nonrepairable, it will be surplussed or scrapped after turn-in to the S\&OC. Any SRIJ's removed from the LRU during the maintenance cycle that are coded as nonrepairable, likewise will be surplussed or scrapped.

\subsection{Unscheduled offline Maintenance Flow. Basic functions necessary to} perform offline maintenance for an unscheduied LRU removal are shown in fiqure 2-i0. When a malfunction or anomaly is isolated to an LRU, onl ine maintenance will remove aid replace and generate the appropriate problem report on the MFTF-B OSM work order.

With prior approval fram Engineering, the LRU can be sent directiy to Failure Analysis, to offsite through $S \& D C$, or to its prime $S / L$ for test and separation. It would depend upon the nature of the fault and the system team leader's routing instructions. The $S / L$ responsible for the analys is $c$ an amend or require specific routing of the LRU or ic5 SRU's when necessary for the determination and explanation of the cause of malfunction or anomaly.

After the LRU/SRU has undergone necessary evaluation and analys is to close out the problem report to the satisfaction of the system team leader initiating the 


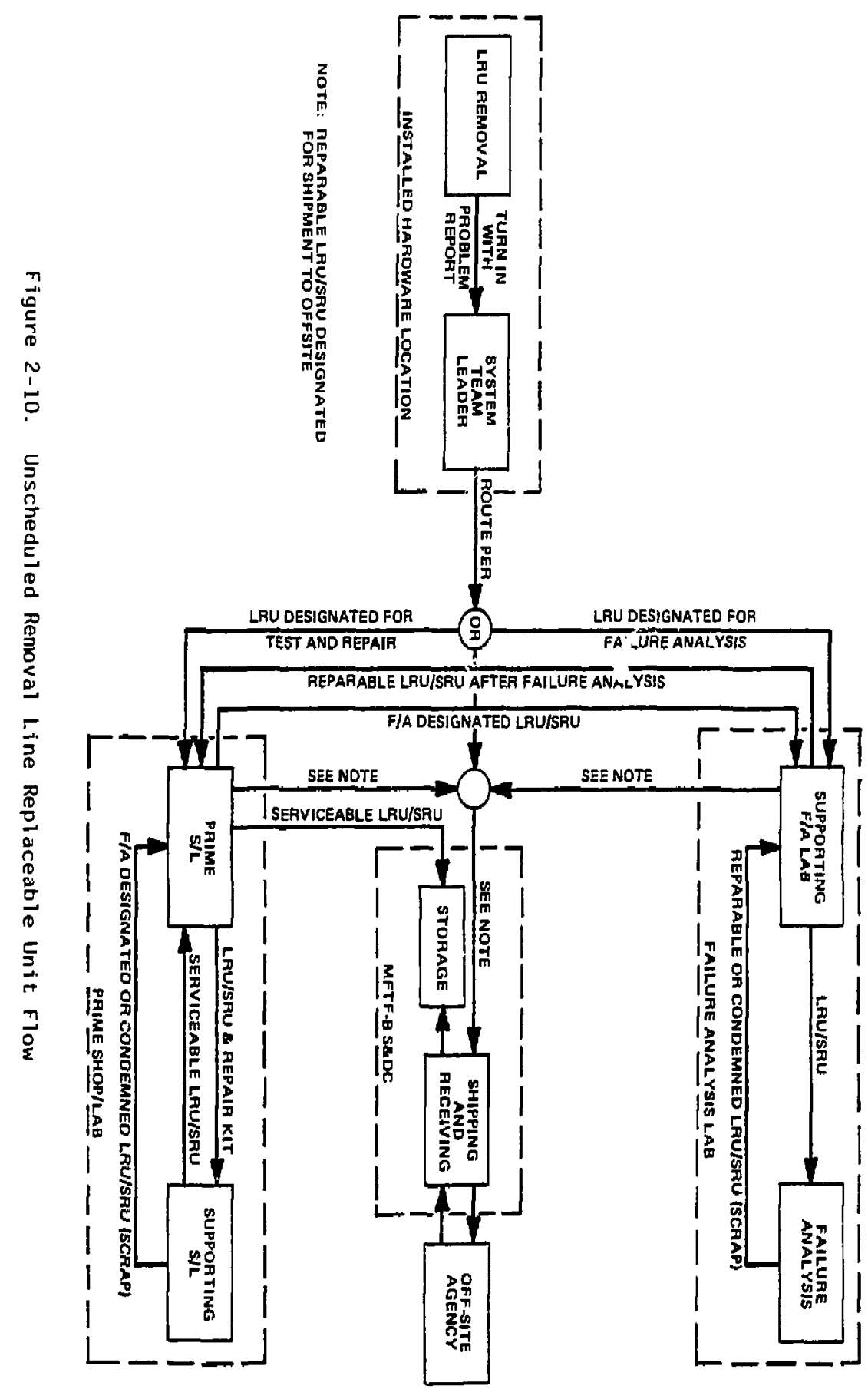


work order, the LRU/SRU will be routed to the prime S/L des ignated for normal item maintenance. Upon completion of repairs, the item(s) will be returned to stock. If an LRU/SRU has been condemned during the evaluation process, it wi:" be surplussed or scrapped.

2.3.4.2 S/L Process Control. The nature : the experimental equipment and the high usage demand of the facility indicate that a significant number of LRU's will be processed through the repair/refurbisment sycle.

The flow of LRU', through the existing LLML shops and labs will be managed by the existing process controls with in those facilities.

The flow of LRU's through the MFTF-B shops requires that internal MFTF-B shop process controls be established to maintain high product quaity and to insure that all work functions are considered in project support scheduling.

The process controls will cover the nomal sequential work activity that mus: occur within the shops. Typical work activity shop action itams are shown in figure 2-11. The sequence may be altered to provide tne correct path for the given requirements of any LRU.

At each action item, the shop Manager will insure compliance with the O\&M Manual procedural requirements and the MFTF- $B$ documentation requirements for the given LRU.

It must be noted that differing paths through the system will occur when:

a. An LRU is sent successively to several different supporting shops.

b. Different SRU's removed from one LRU are sent to different supporting shops.

c. An LRU/SRU is recycled within an S/L. 
PRIME SHOP

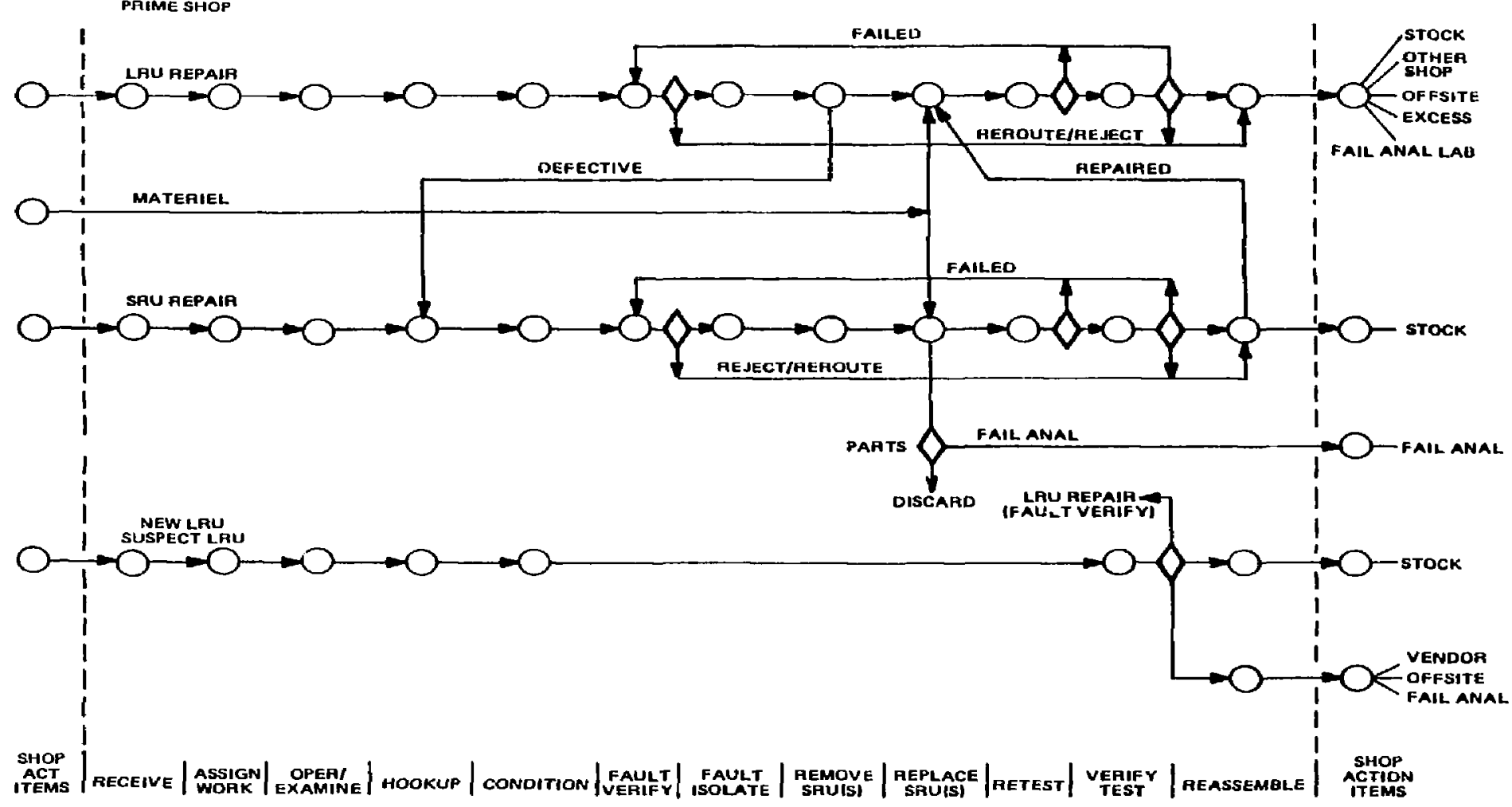

Figure 2-11. Typical Shop Work Activity Flow 
Preplanning of these paths is necessary to support the anticipated mix of LRU types. Periodic updating of the paths and time factors will occur as experience is accumulated.

\subsection{OPERATIONS, MAINTENANCE, AND TRAINING DOCUMENTATION REQUIREMENTS}

Safe and efficient operation of the MFTF-B experiment facility will require clear and concise O\&M documentation and necessary certification training (where required).

The specific requirements will be determined after completion of the following development steps:

a. Def ine the minimum types of documentation required for adequate OtM support for each system and LRU item. Analyze each system against the following checklist:

(1) End-to-end schematics

(2) Indentured drawing list or drawing tree

(3) LRU parts 1 ist and illustrated parts breakdown (IPB)

(4) O\&M requirements and specifications (OMRS)

(5) Ost procedures

(6) Installation drawings/instructions

(7) Safety information

b. Assure that all procured systems and equipment have contracted requirements for OtM manuals and/or installation drawings/operating procedures.

c. Verify or establish schedules for O\&M documentation preparation on systems or equipment manufactured in-house at LLNL.

d. Schedule and prepare total integrated system schematics including instrumentation, diagnostics, and control for the major mechanical and electrical systems. 
e. Schedule and prepare the minimum OHRS that must be met by all online, operating experiment systems. See figure 2-12 for sample format.

f. Determine those systems and equipment that will require formal procedures for operations and maintenance tasks.

NOTE

Each OMRS requirement must be verified at least once by a software program or a hardcopy procedure.

g. Schedule and prepare (as required) procedures or maintenance charts for the following repetitive tasks:

(1) Installation/removal

(2) Inspection/verification

(3) Test/calibration

(4) Servicing/adjustment/a lignment

(5) Cleaning/repair

NOTE

Manufacturer's or vendor's data will be utilized to the maximum extent possible.

h. Identify the training and cert ification record requirements for O\&M personnel. Identify any unique system/equipment safety requirements.

\section{NOTE}

On-the-job (OJT) training is preferred to classroom or audiovisual techniques.

i. Schedule and prepare documentation and/or training equipment as required for any system item that requires formal training techniques.

$j$. Detemine the documentation records required for both real time technical support and management/quality/history purposes. 
<smiles>C1#CC23C4C5C1C52C43</smiles> 
Ident ify documentation record requirements and data storage and retrieval requirements in the following categories:

(1) Inspect ion - receiving, installation, or $S / L$

(2) Servicing/maintenance

(3) Test/calibration

(4) Rework/reidentification

(5) Fault isolation/failure analys is

(6) Safety records [MFTF-B, LLNL, and Occupational Safety and Health Administration (OSHA)]

(7) Provisioning and S\&OC records

\subsection{SPARES PROVISIONING AND SUPPLY OPERATIONS REQUIREMENTS}

2.5.1 SPARES PROVISIONING METHODOLOGY. Spares provisioning to support MFTF-B operations will require utilization of the standard, basic provisioning methodology:
a. Hardware ident if icat ion/costing
b. Budget authorization/funding commitment
c. Spares procurement activities

However, implementation of the above standard processes prior to the experiment operational phase must of necessity rely on assumptions and projections in the many areas of new design.

\subsubsection{Spares Level Philosophy. A minimum/maximum spares level philosophy} will be established by the Associate Program Manager for Engineering (APME) and concurred with by the Associate Program Manager for Operations and Maintenance (APMOM).

The spares level philosophy will stress minimum emphas is on complete LRU assembly stocking and maximum emphasis on LRU/SRU repair parts stocking. Cost factors and repair time vs procurement time factors will be an integral part of the philosophy. 
Stocking of consumables to support more than a 6-month demand will have to be justified on the basis of long term price and del iverability factors.

\subsubsection{Spares Provisioning Phasing. Spares provisioning to support MFTF-B} will be accomplished in two phases:

a. Initial operational spares provisioning

b. Sustaining annual spares provisioning

The initial operational spares will consist primarily of the required complement of complete LRU assemblies necessary to support real time replacements during the experiment run periods.

Procurement action for the initial spares should take place no later than the third quarter of fiscal year (FY) 84 .

The sustaining annual spares will consist primarily of the required complement of LRU/SRU repair parts necessary to sustain the onsite LRU assemblies.

Procurement action for the annual spares shall take place no later than the second quarter of FY 85 and each subsequent year thereafter.

2.5.1.3 Hardware Identification and Costing. Hardware identification and costing will accumulate all available data and data projections from the following sources:

a. Critical LRU maintainability analys is

b. Equipment mean time between failure (MTBF) data/est imates

c. Spare parts lists

d. LLîl experience factors

e. Rome Air Development Command (RADC) standards for new equipment

f. Projected consumables us age rates 
NOTE

Extensive preliminary estimates will have to be utilized during the preoperational phase due to the lack of specific information regarding hardware identification/ costs. For example, the deliverable spare parts list for the cryogenic and external vacuum system is not due until June 30,1984 ,

2.5.1.4 Spare Costs Trade Studies. A spares cost analys is will be prepared to document the trade studies performed prior to final spares procurement recommendations. The analys is report shall include, as a minimum, the information outlined in figure 2-13.

\section{NOTE}

If repair parts are recommended in lieu of complete LRU assemblies for LRU items with cost ratios less than 1.0, witten justification will be required.

\subsubsection{Existing LLNL Piece Part Provisioning. Evaluation of the existing LLNL} standard stock supply of piece parts and attaching hardware will be a prime factor in any repair parts procurement recommendation.

\subsubsection{Provisioning Conferences. A provisioning conference will be held for} each group 1 and group 2 system shown in figure 2-2, no later than the second quarter of FY 84 . The agenda itens will include:

a. Total systen costs per fiscal year

b. Long lead time items list

c. High value iten analys is

d. Make or buy decisions

e. Repair onsite versus offsite

f. Schedules for spares/repair parts/bulk itens/consumables

2.5.1.7 Provisioning Recommendation Authorization. The APMOM will approve the provisioning conference reports and submit them to the APME and the Project Manager for concurrence. 


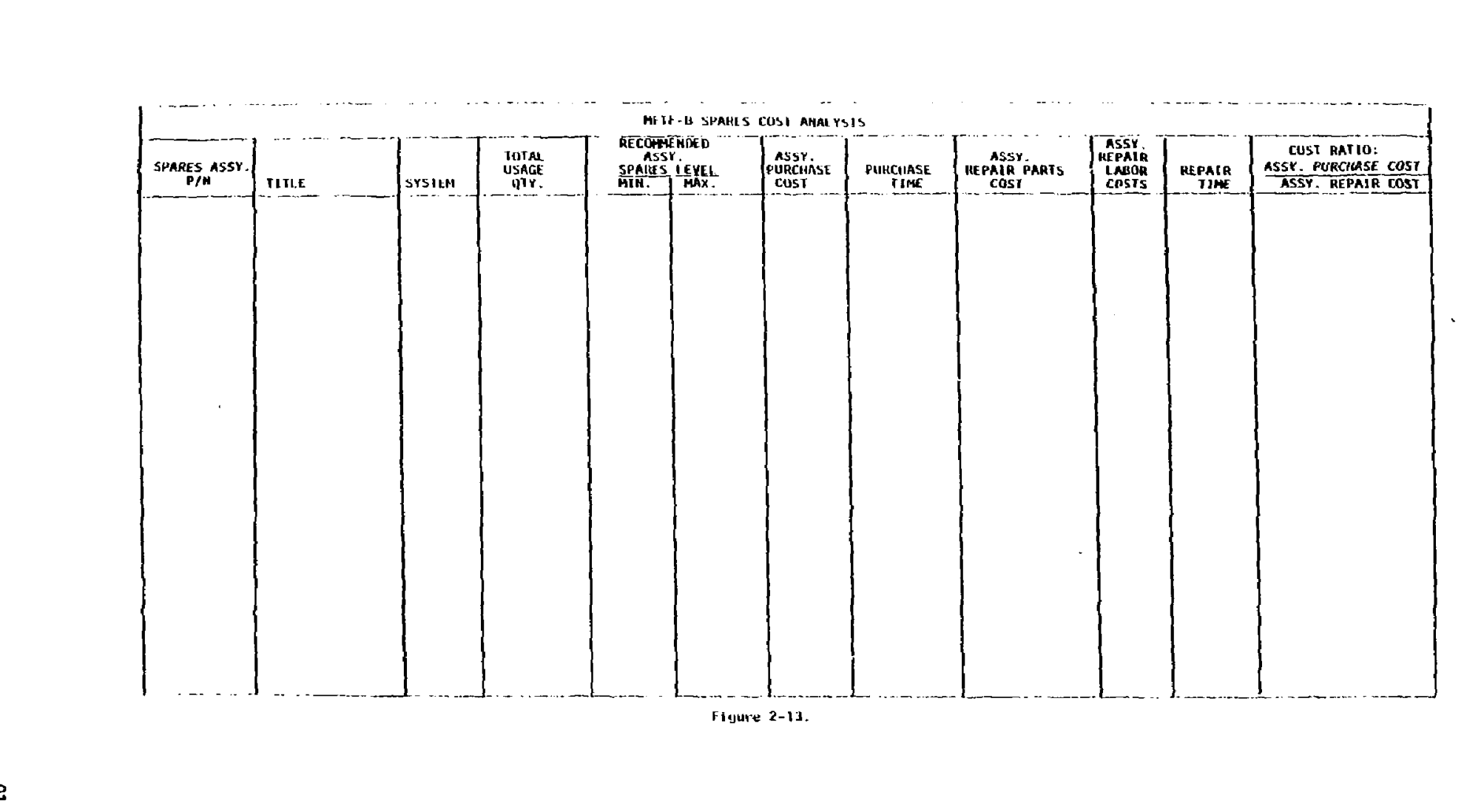


2.5.1.8 Spares Procurement Activities. Existing LLNL S\&DC practices, policies, and forms (e.g., LL4969, LL4869, etc.) will be utilized to obtain the spares and material required to support the MFTF-B operations. Where required, MFTF- $B$ will procure items directly via purchase order, supply contract, or time and material agreement. Hardware procurement via telecon will require APMOM authorization.

\section{NOTE}

To assure validity, the following paragraphs can only be prepared as the ILS development phase is being implemented. Feedback and flexibility are necessary for opt imization prior to the ILS (not MFTF-B) being fully operational.

2.6 ILS Information Management and Work Control Requirements

\subsection{Management Policy and Organization}

III. ILS OPERATIONAL PHASE

3.1 Experiment, Quality and Safety Integration

3.2 Operations, Maintenance and Training Documentation Control

3.3 Maintenance Operations and Trend Analys is

\subsubsection{Online}

\subsubsection{Offline}

\subsection{Supplv Support and Budgets}

3.5 Information and Work Control System 